\title{
Turkish Society of Neuroradiology 31st Year Annual Meeting with Internatonal Participation
}

Published online: 4 January 2022

๑) Springer-Verlag GmbH Germany, part of Springer Nature 2022

Head-Neck Radiology

Ref No: 6

\section{Oral Presentation}

COMPARISON OF PAROTID AND SUBMANDIBULAR SALIVARY GLANDS BENIGN AND MALIGNANT TUMORS WITH MRI FINDINGS

Muhammet Batuhan Gökhan ${ }^{1-2}$, Gülşah Bayram Ilıkan ${ }^{1}$

${ }^{1}$ Ankara City Hospital Radiology Deparment

${ }^{2}$ Ankara Yıldırım Beyazıt Universtiy Radiology Deparment

Objective: Salivary gland tumors constitute $\% 6$ of the head and neck masses with 30 types(1,2). Differentiating benign and malign determining pathological types are important for deciding treatment(3). Radiology has an important role in diagnosis and biopsy(4). Similar tumors can be observed in different glands. Studies showed there is difference in recurrence rates of parotid and submandibular pleomorphic adenomas(PA)(5). We aimed to compare the MRI and demographic differences between different tumors and tumors with the same pathological diagnosis but in different glands.

Materials and methods: From 15.02.2019 to 30.09.2021 356 patients with biopsy for salivary gland lesions were evaluated retrospectively. 15 with history of radiotherapy were excluded. 107 having an MRI before biopsy were included. Images were evaluated without knowledge of diagnosis. Age, gender, lesion side, shape-margin features and diameters were recorded. Average apparent diffusion coefficients(ADC) values, tumor-to-spinal cord signal intensity ratios on T1(T1SIR) and T2(T2SIR) weighted images of lesion were measured by placing $0.2 \mathrm{~cm}^{2}$ ROIs with 5 points at the same level to the spinal cord, avoiding the cystic-necrotic areas. SPSS version 22.0 was used for statistical analysis. Normal distribution was determined by Kolmogorov Smirnov test. Mann Whitney-U, Kruskal Wallis, Chi-Square tests were used for comparing the groups.
Area Under Curve, cut-off point, sensitivity and specificity were calculated. $p<0.05$ was considered statistically significant. The study was approved by Ethical Committee.

Results: The mean age was $53.34 \pm 16.89$ (48 female, 59 male). There were 88 parotid(82.2\%) and 19 submandibu$\operatorname{lar}(17.7 \%)$ lesions. In the parotid lesion group, the mean age was $53.89 \pm 17$. As a result of biopsies, 39 PA, 29 Warthin tumor(WT), 19 malignant tumors(MT)(5 metastases, 1 malignant melanoma, 4 mucoepidermoid, 3 squamous cell(SC), 3 salivary duct, 2 myoepithelial, 1 secretory carcinomas) and 6 other benign tumors(oBT)( 1 oncocytoma, 4 basal cell adenoma, 1 cystadenoma) were diagnosed. In the submandibular group, the mean age was $50.78 \pm 16.62$ and $14 \mathrm{PA}, 1 \mathrm{WT}, 4$ MT(1 SC, 1 adenoid cystic carcinoma, 2 metastases) were diagnosed(Table1). A significant difference was observed between benign and malign tumors in terms of border and shape $(p=0.00, p=0.00)$. There were significant differences in age, mean ADC, T1SIR and T2SIR values between PA and WT, PA and MT, WT and MT and between all three(Table 1). We also detected significant differences in short axis length, T1SIR and T2SIR values between PAs on parotid and submandibular glands $(\mathrm{p}<0.05)$ (Table 2$)$. ROC analyses, cut off, specificity and sensitivity values are shown in Table 3 .

Conclusion: Recurrence of PA is up to 7\% in parotid gland whereas it is extremely rare in submandibular $\operatorname{PA}(6,7)$. Some studies shows that this difference is caused by histopathological subtypes, capsule integrity and microsatellites $(5,8)$. The differences in the evaluation of ADC and T1SIR shown in our study might be due to these pathological features. Differentiation of salivary gland tumors from each other is important for the selection of the appropriate treatment(3). ADC, T1SIR and T2 SIR values can be used in this distinction alongside conventional MRI features and may be important in detailing the pathological diagnosis and increasing the frequency of follow-up depending on the risk of recurrence. 
Keywords: Head, Neck, Salivary Glands, Neoplasms, Carcinomas, Biopsy, Magnetic Resonance Imaging, Pathology

\section{References:}

1) Frade Gonzalez C, Lozano Ramirez A, Garcia Caballero T, Epidemiological study of salivary gland tumours. Rev Laryngol Otol Rhinol (Bord). 1999;120(5):331-336

2) Spiro RH. Salivary neoplasms: overview of a 35-year experience with 2,807 patients. Head Neck Surg. 1986;8(3):177-184 doi:10.1002/hed.2890080309

3) Fernandes H, D'souza CR, Khosla C, George L, Role of FNAC in the Preoperative Diagnosis of Salivary Gland Lesions. J Clin Diagn Res. 2014;8(9):FC01-FC3 doi:10.7860/JCDR/2014/6735.4809

4) Terra GT, Oliveira JX, Hernandez A, Lourenço SV, Diffusion-weighted MRI for differentiation between sialadenitis and pleomorphic adenoma. Dentomaxillofac Radiol. 2017;46(1):20160257 doi:10.1259/dmfr.20160257

5) Mantsopoulos K, Sievert M, Iro AK, et al. Histopathological comparison of pleomorphic adenomas of the parotid and submandibular gland [published online ahead of print, 2021 Mar 26]. Oral Dis. 2021;10.1111/odi.13858. doi:10.1111/ odi. 13858

6) Valstar MH, Andreasen S, Bhairosing PA, Natural history of recurrent pleomorphic adenoma: implications on management. Head Neck. 2020;42(8):2058-2066 doi:10.1002/ hed. 26137

7) Witt RL, Eisele DW, Morton RP, Nicolai P, Poorten VV, Etiology and management of recurrent parotid pleomorphic adenoma. Laryngoscope. 2015;125(4):888-893 doi:10.1002/ lary.24964

8) PATEY DH, THACKRAY AC. The treatment of parotid tumours in the light of a pathological study of parotidectomy material. Br J Surg. 1958;45(193):477-487. doi:10.1002/ bjs. 18004519314

Pediatric Neuroradiology

Ref No: 7

\section{Oral Presentation}

\section{THE EFFECT OF AGE AND GENDER ON CERE- BRAL WHITE MATTER DIFFUSIVITY CHANGES IN CHILDREN.}

Merter Keçeli ${ }^{1}$, Nadide Başak Gülleroğglu ${ }^{1}$, Ayşe Seçil Ekşioğlu ${ }^{1}$

${ }^{1}$ Ankara Bilkent City Hospital, Children Hospital

Objective: Myelination is a dynamic process that continues after birth. One of the MR imaging techniques diffusionweighted imaging (DWI) and measurement of apparent diffusion coefficient (ADC) is a guide for normal brain development. The aim of this study is to show the role of DWI and ADC maps in monitoring the normal development of myelination in children, and to determine ADC values in corpus callosum (CC) and temporal regions (TL).

Material and methods: A total of 112 children (mean age $98 \pm 52.9$ months), 57 of whom were male, were included in the retrospective study in which MRI images were reevaluated. Participants were divided into four age groups between 0 and 202 months. DWI and ADC maps were obtained from both sides of CC and parahippocampal sulcus white matter in both TL. Averages of ADC values were determined.

Results: It was found that ADC values decreased in all measurement areas as the age progressed $(\mathrm{p}<0.005)$. This change was significant on both sides of the TL and left half of the $\mathrm{CC}$ genu and body. ADC value did not change according to gender and measured side.

Conclusion: $\mathrm{ADC}$ values decrease with progressive increase of age. Using ADC values of CC and TL, the development of normal myelination in the brain and changes caused by puberty can be distinguished from other pathologies.

Keywords: ADC, corpus callosum, temporal lobe, children, puberty, gender

\section{References:}

1. Deoni SC, Mercure E, Blasi A, Gasston D, Thomson A, Johnson M, et al. Mapping infant brain myelination with magnetic resonance imaging. J Neurosci 2011;31(2):784-91. 2. Aubert-Broche B, Fonov V, Leppert I, Pike GB, Collins DL. Human brain myelination from birth to 4.5 years. Med Image Comput Comput Assist Interv 2008;11(Pt. 2):180-7. 3. Tortori- Donati P, Biancheri R, Rossi A, Raybaud C. Pediatric neuroradiology: brain head, neck and spine. Edition number:1. New York: Springer; 2010. p. 21-40.

4. Brody BA, Kinney HC, Kloman AS, Gilles, FH. Sequence of central nervous system myelination in human infancy. I. An autopsy study of myelination. J. Neuropathol. Exp. Neurol. 1987;46, 283-301.

5. Hermoye L, Saint-Martin C, Guy C. et al. Pediatric diffusion tensor imaging: Normal database and observation of the white matter maturation in early childhood, NeuroImage 29 (2006) 493 - 504.

6. Barkovich AJ. Concepts of myelin and myelination in neuroradiology. AJNR Am J Neuroradiol 2000;21:1099-109.

7. Counsell SJ, Maalouf EF, Fletcher AM, Duggan P, Battin M, Lewis HJ, et al. MR imaging assessment of myelination in the very preterm brain. AJNR Am J Neuroradiol (2002);23:872-81.

8. Ladoucer CD, Pepper JS, Crone EA, Dahl RE. White matter development in adolescence: The influence of puberty 
and implications for affective disorders. Developmental Cognitive Neuroscience 2 (2012) 36- 54.

Adult Neuroradiology

Ref No: 9

\section{Poster Presentation}

\section{AN INCIDENTAL TECTAL PLATE LIPOMA}

$\underline{E \text { Eda Cingöz }}{ }^{1}$, Rana Günöz Cömert ${ }^{2}$, Zeynep Nur Akyol Sarr $^{1}$, Mehmet Cingöz ${ }^{3}$, Mehmet Barburoğlu ${ }^{1}$

${ }^{1}$ İstanbul University Medical Faculty

${ }^{2}$ Tokat Turhal State Hospital

${ }^{3}$ Başakşehir Çam And Sakura City Hospital

Objective: Intracranial lipomas are rare, slow-growing, benign, congenital lesions accounting for $0.1-0.5 \%$ of all primary brain tumors(1). Tectal plate lipomas constitute approximately $25 \%$ of intracranial lipomas and are located within the quadrigeminal cistern(2). Although they are asymptomatic and found incidentally, they can cause mass effect resulting in hydrocephalus or seizures very rarely(3). Surgical management can be considered if there is a mass effect(4). The differential diagnoses are tectal plate glioma, tectal plate cyst, arachnoid cyst, dermoid cyst and epidermoid cyst(3). It is also known as quadrigeminal cistern lipoma, quadrigeminal plate lipoma, superior vermis lipoma and superior medullary velum lipoma. The diagnosis is always certain on imaging, and therefore histopathological confirmation is never practically required.

Case Presentation: A 63-year old male patient is referred to the radiology department to obtain intracranial and extracranial MRA with a prediagnosis of probable arterial occlusion. The MRA images demonstrated no occlusion within cerebral vascular structures but incidentally, a left tectal plate mass is noticed. To reveal the signal characteristics of the lesion, a contrast-enhanced brain MRI is planned. The lesion can not be appreciated on axial T2-weighted images and flair sequence. Axial and sagittal T1-weighted images clearly demonstrated a lesion located at the left quadrigeminal cistern abutting the tectal plate. The postcontrast image showed no difference from the precontrast $\mathrm{T} 1$-weighted image. The lesion was reported as tectal plate lipoma that was found incidentally.

Conclusion: Intracranial lipomas are not very common in the population. The tectal plate is even a rarer location for intracranial lipoma. When one keeps in mind that the tectal plate is a possible location for a lipoma, then it is not very hard to diagnose a tectal plate lipoma just by looking at T1-weighted images. The radiologic diagnosis is so confident that there is no requirement for histopathological verification. Intracranial lipomas do not cause any symptoms except very rare instances i.e. when it hinders the passage of cerebrospinal fluid and causes hydrocephalus.

Keywords: lipoma, brain

\section{References:}

1. Nikaido Y, Imanishi M, Monobe T. Lipoma in the quadrigeminal cistern - case report. Neurol Med Chir (Tokyo). 1995;35:175-178.

2. Truwit CL, Barkovich AJ. Pathogenesis of intracranial lipoma: an MR study in 42 patients. AJR Am J Roentgenol. 1990;155 (4): 855-64.

3. Ogbole G, Kazaure I, Anas I. Quadrigeminal plate cistern lipoma. (2009) BMJ case reports.

4. Maiuri F, Cirillo S, Simonetti L et-al. Intracranial lipomas. Diagnostic and therapeutic considerations. J Neurosurg Sci. 1989;32 (4): 161-7.

Adult Neuroradiology

Ref No: 10

\section{Oral Presentation}

EVALUATION OF CRANIAL LIPOMAS WITH SUSCEPTIBILITY-WEIGHTED IMAGING $\underline{A D E M ~ Y O K U S}^{1}$

${ }^{1}$ Van Yüzüncü Yll University, Department Of Radiology, Van, Turkey

Objective: Susceptibility weighted imaging (SWI) creates contrast differences between adjacent tissues using focal tissue susceptibilities. In this study, our aim is to describe the blooming that occurs in cranial lipomas and to discuss its relationship with localization.

Material and methods: Patients who underwent cranial MRI and CT imaging and detected lipoma in our hospital between January 2014 and December 2020 were analyzed retrospectively. 29 patients (16 male, 13 female, mean age $46.82 \pm 15.56$ years, age range:18-74) who had brain CT and MRI with SWI were included in the study. CT images were examined to confirm fat density and to evaluate calcification content. MR imaging was performed using a 1.5 Tesla scanner (Magnetom-Symphony, SiemensMedical-Systems, Erlangen-Germany). Parameters for SWI were as follows: TR/TE:50/40 ms, slice thickness:3mm, matrix:395x574, FOV:220mm, bandwidth:80kHz, acquisition time:3.03minutes.

Results: Location of intracranial lipomas was as follows: 5 choroid plexus, 4 quadrigeminal cistern, 3 parafalcine, 1 pineal, 6 pericallosal, 1 suprasellar, 2 tentorium, 7 scalp. Five 
pericallosal lipomas were curvilinear type, and complete blooming was observed. Peripheral blooming was present in tubulonodular type. Complete blooming was detected in lipomas located in the choroid plexus, parafalcine, suprasellar and tentorium. Of quadrigeminal lipomas, 3 were complete, and 1 showed peripheral blooming. In pineal lipoma, there was peripheral blooming as well as central punctate blooming. Peripheral blooming was observed in subcutaneous lipomas. Corpus callosum dysgenesis in three patients and focal cortical dysplasia in one patient with pericallosal lipoma, epidermoid cyst in one patient with choroid plexus lipoma, and arachnoid cyst in one patient with suprasellar lipoma were detected as associated anomalies.

Conclusion: Peripheral blooming in subcutaneous lipomas can be explained by the minimal chemical shift between subcutaneous adipose tissue and adipose tissue of lipoma. The most obvious cause of complete blooming in intracranial lipomas is probably the strong chemical shift between adipose tissue and CSF. The reduction in short diameter in lipomas may contribute to the formation of complete blooming, with the incorporation of blooming on opposing walls. For example, the short diameter of the quadrigeminal lipoma with peripheral blooming was $7.3 \mathrm{~mm}$, while the diameter was $1.7 \mathrm{~mm}, 1.8 \mathrm{~mm}$, and $5 \mathrm{~mm}$, respectively, in those with complete blooming. It can be thought that contour lobulation in intracranial lipomas, especially in pericallosal lipomas, aggravates the blooming artefact by increasing the chemical shift and intravoxel phase shift. During the embryonic period, microscopic calcification and mineralization occur in the differentiation process of the meninx primitiva into lipoma. Central punctate blooming detected in the pineal lipoma may be due to these microscopic calcifications and/or mineralizations.

Keywords: Complete blooming, Cranial lipoma, Peripheral blooming, Susceptibility-weighted imaging

\section{References:}

1. Mehemed TM, Yamamoto A, Okada T, Kanagaki M, Fushimi Y, Sawada T, Togashi K. Fat-water interface on susceptibility-weighted imaging and gradient-echo imaging: comparison of phantoms to intracranial lipomas. AJR Am J Roentgenol. 2013 Oct;201(4):902-7.

2. Lingegowda D, Rajashekar C, Belaval VV, Thomas B, Keshavdas C; Kapilamoorthy. Susceptibility artifacts in lipomas. Neurol India. 2013 Jan-Feb;61(1):56-9.

3. Truwit CL, Barkovich AJ. Pathogenesis of intracranial lipoma: an MR study in 42 patients. AJR Am J Roentgenol. 1990 Oct;155(4):855-64.

Adult Neuroradiology

Ref No: 20

\section{Oral Presentation}

RELATIONSHIP BETWEEN PRESENCE AND LOCATION OF ARTERIAL TRANSIT ARTIFACTS SEEN ON ARTERIAL SPIN LABELING AND DIGITAL SUBTRACTION ANGIOGRAPHY STENOSIS PERCENTAGE IN PATIENTS WITH INTERNAL CAROTID ARTERY STENOSIS

Rifat $\ddot{O}_{z \text { par }}{ }^{1}$, Yasemin Dinç ${ }^{2}$, Gökhan Öngen ${ }^{1}$, Bahattin Hakyemez ${ }^{1}$

${ }^{I}$ Department Of Radiology, Bursa Uludag University Faculty Of Medicine

${ }^{2}$ Department Of Neurology, Bursa Uludag University Faculty Of Medicine

Objective: Arteriyel transit artifact (ATA) is an artifact seen on arterial spin labeling (ASL) perfusion magnetic resonance imaging (MRI) (1). They represent the protons not reached to parenchymal level, and they are observed in a vessel with slow flow due to proximal stenosis or collateral flow secondary to proximal occlusion (2). In the case of arterial stenosis, their localization may correlate with the percentage of stenosis. Our aim was to evaluate the correlation between the presence and localization of ATAs and the percentage of stenosis in internal carotid artery (ICA) stenosis patients.

Materials and Methods: The study was approved by Bursa Uludag University Faculty of Medicine Clinical Research Ethics Committee (Decision Number: 2021-18/16). Seventeen patients with significant degree ( $>50)$ unilateral ICA stenosis diagnosed with Digital Subtraction Angiography (DSA) and went to ASL Perfusion MRI imaging in the same period with DSA between May 2020 - March 2021 were included in our study. Presence, localization of ATAs, hypoperfusion presence on ASL perfusion imaging, and demographic findings were determined. Patients were grouped according to ASL presence and localization. Groups were compared for the significant difference between stenosis percentages.

Results: Mean, standard deviation, minimum, and maximum rates of stenosis were $\% 76.2,15.9,51,99.9$, respectively. ATA was seen in \%70.6 (12/17) of patients, \%35.3 (6/17) in ICA and middle cerebral artery (MCA), 23.5\% (4/17) in the distal branch of MCA only, 11.8\% (2/17) in ICA only. The stenosis rate was significantly higher in patients with ATA than patients without ATA $(\% 84.3 \pm 10.7$ vs. $\% 56.7 \pm$ $5.23, \mathrm{p}=0.002)$. Stenosis rates were significantly different between groups with different ATA localizations $(p=0.013)$. The mean rate of stenosis was $\% 95.7 \pm 5.9$ in the patients with ATA seen in ICA only, $\% 88.4 \pm 3.5$ in the patients with 
ATA seen in ICA and MCA, \%72.5 \pm 9.1 in the patients with ATA seen in the distal branches of MCA.

Conclusion: ATAs are primarily described as a finding of collateralization in the setting of stroke or Moya - Moya syndrome $(3,4)$. ATA presence has been found to be correlated with severe (>70\%) stenosis and symptoms in carotid artery stenosis patients (5). However, ATA presence may produce errors in CBF quantification of ASL (6). There is no study investigating the relationship between ATA localization and stenosis severity in the literature. In conclusion, ATA presence in ICA - MCA territory may represent a severe degree of proximal ICA stenosis. Also, the presence of ATA in ICA may be the reflection of a critical level ICA stenosis. In the evaluation of ASL, care must be taken for ATA in ICA or MCA territory in carotid artery stenosis patients.

Keywords: Perfusion Magnetic Resonance Imaging, Internal Carotid Artery Stenosis, Angiography, Digital Subtraction

\section{References:}

1) Deibler AR, Pollock JM, Kraft RA, et al. Arterial spin-labeling in routine clinical practice, part 1: technique and artifacts. AJNR Am J Neuroradiol. 2008;29:1228-34.

2) Ferré JC, Bannier E, Raoult H, et al. Arterial spin labeling (ASL) perfusion: techniques and clinical use. Diagn Interv Imaging. 2013;94:1211-23.

3) de Havenon A, Haynor DR, Tirschwell DL, et al. Association of Collateral Blood Vessels Detected by Arterial Spin Labeling Magnetic Resonance Imaging With Neurological Outcome After Ischemic Stroke. JAMA Neurol 2017;74:453-8.

4) Ukai R, Mikami T, Nagahama H, Wanibuchi M, Akiyama Y, Miyata K, Mikuni N. Arterial transit artifacts observed by arterial spin labeling in Moyamoya disease. J Stroke Cerebrovasc Dis. 2020;29:105058.

5) Di Napoli A, Cheng SF, Gregson J, et al. Arterial Spin Labeling MRI in Carotid Stenosis: Arterial Transit Artifacts May Predict Symptoms. Radiology. 2020;297:652-60.

6) Fahlström M, Lewén A, Enblad P, Larsson EM, Wikström J. High Intravascular Signal Arterial Transit Time Artifacts Have Negligible Effects on Cerebral Blood Flow and Cerebrovascular Reserve Capacity Measurement Using Single Postlabel Delay Arterial Spin-Labeling in Patients with Moyamoya Disease. AJNR Am J Neuroradiol. 2020;41:430-6.

Adult Neuroradiology

Ref No: 21

\section{Oral Presentation}

DIAGNOSTIC EFFICIENCY OF MULTIPARAMETRIC MRI TO ASSESS IDH-1 MUTATION STATUS OF ADULT ASTROCYTOMA

Nail Bulakbaşı ${ }^{1}$, Uğurcan Balyemez ${ }^{2}$, Mehmet Alp Dirik ${ }^{1}$, Özüm Tunçyürek ${ }^{2}$

${ }^{1}$ University Of Kyrenia

${ }^{2}$ Near East University

Objective: Multiparametric MRI has long been used for brain tumor diagnosis. In $2021 \mathrm{WHO}$ classification of tumor of the central nervous system, adult-type astrocytoma is classified as isocitrate dehydrogenase-1 (IDH-1) mutant $\left(\mathrm{IDH}_{\mathrm{m}}\right)$ and IDH-1 wildtype $\left(\mathrm{IDH}_{\mathrm{wt}}\right)$, aka glioblastoma (1). IDH1 status has also a similar prognostic value as the tumor grade (1). We prospectively evaluated the diagnostic efficiency of different MR parameters calculated from multiparametric MRI to detect the IDH-1 mutation status of adult astrocytoma.

Materials and methods: Forty-three lesions revealed in 28 adult patients ( 9 women, 19 men ranging 34-89 years old of age) with histologically proven $16 \mathrm{IDH}_{\mathrm{m}}$ and $27 \mathrm{IDH}_{\mathrm{wt}}$ astrocytomas were prospectively evaluated with multiparametric MRI. Besides anatomic imaging, contrast-enhanced $\mathrm{T} 2 *$ and $\mathrm{T} 1$ weighted perfusion, diffusion, diffusion kurtosis images, and multivoxel MR spectroscopy ( $\mathrm{TE}=144 \mathrm{~ms}$ ) were obtained on a $3 \mathrm{~T}$ MR scanner. ROIs were manually drawn from tumoral areas by avoiding regions with large necrosis, hemorrhages, cysts, and large vessels. All parameters except spectroscopic data in tumors were normalized to that in contralateral normal-appearing white matter. The normalized ADC, rCBV, Ktrans, Kep, Ve, iAUC, $\mathrm{Chi}^{2}$, ADC-K, ADC computed, ADC threshold, kurtosis, DKI-D, DKI computed values, and $\mathrm{Cho} / \mathrm{Cr}$ and $\mathrm{NAA} / \mathrm{Cr}$ ratios were calculated by standard software and statistically tested by the independent sample t-test assuming unequal variances, 2-tailed Pearson correlation coefficients and ROC analysis independently.

Results: IDH1/2 mutation status were accurately detected by normalized rCBV $\left(\mathrm{IDH}_{\mathrm{m}}=086 \pm 0,39 \mathrm{vs} \mathrm{IDH}_{\mathrm{wt}}=2,37 \pm 1,07\right)$, Ktrans $\left(\mathrm{IDH}_{\mathrm{m}}=0,80 \pm 0,70\right.$ vs $\left.\mathrm{IDH}_{\mathrm{wt}}=3,92 \pm 2,81\right), \mathrm{Chi}^{2}$ $\left(\mathrm{IDH}_{\mathrm{m}}=1,03 \pm 0,57 \mathrm{vs} \mathrm{IDH}_{\mathrm{wt}}=2,77 \pm 1,57\right)$, ADC threshold $\left(\mathrm{IDH}_{\mathrm{m}}=0,80 \pm 0,13\right.$ vs $\left.\mathrm{IDH}_{\mathrm{wt}}=0,95 \pm 0,12\right)$, and kurtosis $\left(\mathrm{IDH}_{\mathrm{m}}=0,55 \pm 0,11 \mathrm{vs} \mathrm{IDH}_{\mathrm{wt}}=0,86 \pm 0,22\right)$ values $(p<.001)$ (Fig 1). IDH-1 mutation is correlated with $\mathrm{rCBV}(0.645, p$ $<.001)$, Ktrans $(0.561, p<.001), \mathrm{Chi}^{2}(0.552, p<.001)$, ADC threshold $(0.543, p<.001)$ and kurtosis $(0.642, p<$ $.001)$ values. Among these parameters, the cutoff value of normalized kurtosis ratio of 0,66 (ROC:0,979), the Ktrans ratio of 1,43 (ROC:0,972), and the rCBV ratio of 1,46 
(ROC:0,965) have the same diagnostic accuracy (sensitivity: $90,9 \%$, specificity: $7,7 \%, p<.001)$ to assess the IDH-1 mutation status followed by the cutoff value of $\mathrm{Chi}^{2}$ ratio of 0,98 (ROC:0,930) with 90,9 sensitivity and \%3,85 specificity $(p<.001)$ and the ADC threshold of 0,88 (ROC:0,902) with $81,8 \%$ sensitivity and $\% 1,54$ specificity $(p<.001)$ (Fig 2).

Conclusion: Multiparametric MRI is a very useful technique for the noninvasive assessment of the IDH-1 mutation status of astrocytoma. A combination of different parameters and their cutoff values obtained from different advanced MRI techniques is quite useful for the accurate detection of the IDH-1 mutation status of the tumor.

Keywords: IDH mutation, Astrocytoma, Multiparametric Magnetic Resonance Imaging, Kurtosis

\section{References:}

1. Louis DN, Perry A, Wesseling P, Brat DJ, Cree IA, Figarella-Branger D, Hawkins C, Ng HK, Pfister SM, Reifenberger G, Soffietti R, von Deimling A, Ellison DW. The 2021 WHO Classification of Tumors of the Central Nervous System: a summary. Neuro Oncol. 2021;23(8):1231-1251.

Head-Neck Radiology

Ref No: 22

\section{Oral Presentation}

\section{EVALUATION OF THE RELATIONSHIP BETWEEN PATHOLOGICAL DIAGNOSIS AND MAGNETIC RESONANCE IMAGING FINDINGS IN PATIENTS WHO UNDERWENT ULTRASOUND-GUIDED BIOPSY FOR PAROTID GLAND MASS}

$\underline{\text { Leyla Mirzayeva }}^{1}$, Mahinur Cerit ${ }^{1}$, Emetullah Cindil ${ }^{1}$

${ }^{1}$ Gazi University Faculty Of Medicine

Objective: Fine needle aspiration biopsy (FNAB) and core needle biopsy (CNB) are safe methods used in the definitive diagnosis of parotid gland masses with suspected neoplasia [1-3]. In this study, we aimed to evaluate the correlation between pathological diagnosis and magnetic resonance imaging findings in patients who underwent ultrasoundguided biopsy for parotid gland mass.

Materials and methods: The clinical records of 50 patients who underwent magnetic resonance imaging (MRI) before biopsy were reviewed retrospectively. After needle biopsy total excisional surgery was performed in 22 cases. We compared the diagnostic accuracy of MRI with incisional and excisional biopsy results. Statistical analyses were done using SPSS for Windows 11.5(SPSS Inc, Chicago, IL, USA).
Pearson Chi-Square test was used to compare the preoperative MRI diagnoses and the pathological examination diagnoses after biopsy. In addition, preoperative MRI diagnoses and surgical histopathological diagnoses were compared in patients who underwent surgery after biopsy. P-value $<0.05$ was considered statistically significant.

Results: Twenty-three $(46.0 \%)$ patients were female and $27(54.0 \%)$ patients were male. The median age at presentation was 58.0 (mean:55.8, range:22-89) years. There were cystic components in $18(36.0 \%)$ masses on MRI. After intravenous contrast medium administration, contrast enhancement was observed in 45(90.0\%) masses on T1-weighted MRI. MRI appearances of parotid lesions were compatible with pleomorphic adenoma in 13 cases, Warthin's tumor in 12 cases, lymphadenopathy in 5 cases, normal lymph node in 5 cases, metastasis in 5 cases, mucoepidermoid cancer in 1 case, adenoid cystic carcinoma in 1 case, lymphoma in 1 case, venous malformation in 1 case, acute parotitis in 1 case, and cyst in 1 case. FNAB was performed in 39 and CNB in 11 cases. MRI diagnosis and pathological examination diagnoses were parallel in $10(77.0 \%)$ pleomorphic adenoma cases, in $8(66.7 \%)$ Warthin's tumor cases, in $3(60.0 \%)$ metastasis cases, in $2(40.0 \%)$ lymphadenopathy cases, in $2(40.0 \%)$ reactive lymph node cases, in $1(100 \%)$ mucoepidermoid cancer case, and 1(100\%) lymphoma case $(\mathrm{p}=0.009)$. An excisional biopsy was performed in 22 cases. Correlation between MRI diagnoses and pathological results was reported in 4/6(66.7\%) Warthin's tumor, in 7/7(100.0\%) pleomorphic adenoma, in $2 / 3(66.7 \%)$ metastasis, and in $1 / 2(50.0 \%)$ mucoepidermoid cancer cases $(\mathrm{p}=0.067)$.

Conclusion: The accuracy rate of MRI in the diagnosis of parotid gland tumors was $63.6 \%$. MRI diagnoses and biopsy results were statistically compatible $(\mathrm{p}=0,009)$. In parotid gland masses, the accuracy, sensitivity, and specificity rates of MRI were reported $88.4 \%, 81.2 \%$, and $90.5 \%$ respectively [4]. MRI can play an important role in the diagnosis and surgical planning of parotid masses.

Keywords: Magnetic Resonance İmaging, Parotid gland, Ultrasound-guided biopsy

\section{References:}

1. Cengiz AB, Tansuker HD, Gul R, Emre F, Demirbas T, Oktay MF. Comparison of preoperative diagnostic accuracy of fine needle aspiration and core needle biopsy in parotid gland neoplasms. Eur Arch Otorhinolaryngol. 2021 Oct;278:4067-4074.

2. Haldar S, Sinnott JD, Tekeli KM, Turner SS, Howlett DC. Biopsy of parotid masses: Review of current techniques. World J Radiol. 2016;8:501-505. 
3. Sharma G, Jung AS, Maceri DR, Rice DH, Martin SE, Grant EG. US-guided fine-needle aspiration of major salivary gland masses and adjacent lymph nodes: accuracy and impact on clinical decision making. Radiology. 2011 May;259:471-8.

4. Şahin M. M. , Çayönü M. , Sözmen Cılız D. , Ünsal Tuna E. E. , Kayalı Dinç A. S. , Boynueğri S. , Eker Barut F. , Sakman B. , Eryılmaz A. Magnetic Resonance Imaging versus Fine Needle Aspiration Biopsy in the Differential Diagnosis of Neoplastic Parotid Gland Lesions. ENT Updates. 2019; 9(1): 38-43.

Adult Neuroradiology

Ref No: 23

\section{Poster Presentation}

\section{A FORGETTEN RADIOCONTRAST: IOFENDYLATE (MYODIL) \\ Muhammet Batuhan Gökhan ${ }^{1-2}$ \\ ${ }^{1}$ Ankara City Hospital Radiology Department \\ ${ }^{2}$ Ankara Ylldırım Beyazıt University Radiology Department}

Objective: Recognition to deposit due to contrast agents is important for accurate diagnosis. Effects due to withdrawn contrast agents may be overlooked, especially by the new generation of radiologists who had not used these methods. Iofendylate is one of such oli-based contrast agents used in myelography from 1944 to 1988 (1). However, it was withdrawn due to the risk of severe arachnoiditis (2).

Case Presentation: 69 years old woman had been admitted to the emergency department for syncope and headache. In her systemic history she had diabetes mellitus, hypertension, chronic kidney disease and coronary artery disease. Her physical examination and laboratory studies were normal. In the cranial computered tomography (CT) taken in our department, senile and chronic ischemic changes and multiple milimetric calcifications in the subarachnoid space were detected. When the clinical history was questioned again, she stated that she had a myelography when she was 30 years old. The patient was discharged after symptomatic treatment.

Conclusion: Many different contrast agents have been used in radiological imaging throughout history, and some of them have been withdrawn due to their side effects and the availability of more effective contrasts or imaging methods (3). Some drugs and contrast agents can accumulate in various tissues (4). Because of this phenomenon, radiologist should be aware of such deposits to avoid misdiagnosis. Intracranial calcifications are frequently encountered in radiology practice. Depending on age and neurodegeneration, they are observed in the parenchyma, pineal gland, habenula, choroid plexus, basal ganglia and dura (5). In addition, we can see calcifications after some infections and vascular malformations. Nodular subarachnoid calcifications may also be encountered in remnants of cysticercosis and toxoplasma infection (6). Iofendylate was that used for myelography from 40 s to the late 80 s. Since the first periods of its use, there are studies in the literature showing arachnoiditis and related adhesions and subarachnoid-subdural nodular calcifications in the intracranial and spinal region $(7,8)$. Iofendylate was withdrawn because of serious arachnoiditis and with the increasing number of water-soluble contrasts(1). Knowing this kind of side effects of contrast agents is important to correct diagnosis especially by the new generation of radiologists who had not used these methods.

Keywords: Contrast, Iofendylate, Arachnoiditis, Myelography

\section{References:}

1) Lutters B, Groen RJM, Koehler PJ. Myelography and the 20th Century Localization of Spinal Cord Lesions. Eur Neurol. 2020;83(4):447-452. doi:10.1159/000509863

2) Pawl R. History of myelography with pantopaque contributing to arachnoiditis. Surg Neurol Int. 2014;5(Suppl 7):S315-S316. Published 2014 Aug 28. doi:10.4103/2152-7806.139617

3) Zamora CA, Castillo M. Historical Perspective of Imaging Contrast Agents. Magn Reson Imaging Clin N Am. 2017;25(4):685-696. doi:10.1016/j.mric.2017.06.002

4) Junck L, Marshall WH. Neurotoxicity of radiological contrast agents. Ann Neurol. 1983;13(5):469-484. doi:10.1002/ ana.410130502

5) Kıroğlu Y, Callı C, Karabulut N, Oncel C. Intracranial calcifications on CT. Diagn Interv Radiol. 2010;16(4):263269. doi:10.4261/1305-3825.DIR.2626-09.1

6) Del Brutto OH, Del Brutto VJ. Intrasellar cysticercosis: a systematic review. Acta Neurol Belg. 2013;113(3):225-227. doi:10.1007/s13760-013-0199-1

7) MASON MS, RAAF J. Complications of pantopaque myelography. Case report and review. J Neurosurg. 1962;19:302-311. doi:10.3171/jns.1962.19.4.0302

8) Oo M, Wang Z, Sakakibara T, Kasai Y. Magnetic resonance imaging findings of remnants of an intradural oil-based contrast agent: report of a case. J Spinal Cord Med. 2012;35(3):187-190. doi:10.1179/20457723 12Y.0000000002

Head-Neck Radiology

Ref No: 25 


\section{Oral Presentation}

EVALUATION OF ARACHNOID GRANULATIONS IN THE CRANIAL DURAL SINUSES WITH CONTRASTENHANCED 3D T1-WEIGHTED MAGNETIC RESONANCE IMAGING

Hatice Kaplanoğlu ${ }^{1}$, Veysel Kaplanoğlu ${ }^{2}$, Aynur Turan ${ }^{1}$, Alper Dilli ${ }^{1}$

${ }^{1}$ Health Sciences University Dışkapı Yıldırım Beyazıt Training And Research Hospital, Department Of Radiology, Ankara, Turkiye

${ }^{2}$ Health Sciences University Keçiören Training And Research Hospital, Department Of Radiology, Ankara, Turkiye

Objective: Several studies in the literature have used contrast-enhanced magnetic resonance imaging (MRI)to investigate arachnoid granulations (AGs) protruding into the cranial dural sinuses. The current study aimed to investigate the protrusion of AGs into the superior sagittal sinus (SSS), transverse sinus (TS), straight sinus (StS) and confluence of sinuses (ConfS) and determine the frequency of brain herniation into giant AGs using contrast-enhanced 3D T1-weighted MRI.

Materials and methods: Images of 300 patients with intra-sinus AGs who underwent contrast-enhanced 3D T1-weighted thin-slice MRI were retrospectively re-evaluated.

Results: A total of 889 focal filling defects of AGs, at least one in the dural sinus, were detected.Of the filling defects of AGs, 183 were in the right TS, 222 in the left TS, 265 in SSS, 185 in StS, and 34 in ConfS. AGs were most common in the anterior superior portion of SSS, at the junction with the vein of Galen and in the lower 1/3 of StS, and in the midlateral portion of TS. Brain herniation into AGs was detected in eight $(2.7 \%)$ of the patients included in the study. All the filling defects detected in the dural sinuses on post-contrast 3D T1-weighted images were isointense with cerebrospinal fluid and had round, oval or lobulated contours. A positive correlation was found between patient age and the size and number of AGs ( $r=0.181, p<0.01$ and $r=0.207, p<0.001$, respectively). It was observed that the size and number of AGs increased as the age of the patients increased.

Conclusion: The distribution, shape, number and size of intra-sinus AGs can vary considerably. Brain herniation into AG can also be seen. 3D cranial MRI sequences can be safely used in the evaluation of AGs.

Keywords: Arachnoid granulations, Dural sinuses, Magnetic resonance imaging, 3D T1-weighted

\section{References:}

1- Ogul H, Guven F, Izgi E, Kantarci M (2019) Evaluation of giant arachnoid granulations with high-resolution 3D-volumetric MR sequences at 3T. Eur J Radiol 121:108722.

2- Genovese M, Galassi G, Capasso R, Malagoli M, Vallone $S$ (2020) Vein of Galen varix associated with straight sinus arachnoid granulation. Acta Neurol Belg 120:463-4646.

3- Tsutsumi S, Ono H, Ishii H. Arachnoid granulations bulging into the transverse sinus, sigmoid sinus, straight sinus, and confluenssinuum: a magnetic resonance imaging study. Surg Radiol Anat. 2021 Feb 26. doi: 10.1007/ s00276-021-02719-4.

4- H. Ogul, M. Kantarci, An unusual cause of progressive headache: herniation of the cerebellar gyrus into the intraosseous arachnoid granulation, Headache 57 (2017) 778-779.

Interventional Radiology

Ref No: 28

\section{Oral Presentation}

\section{TELESCOPIC CONFIGURATION WITH A FLOW DIVERTER DEVICE AND STENT FOR FUSIFORM INTRACRANIAL ANEURYSMS \\ Mehmet Onay ${ }^{1}$, Çetin Murat Altay ${ }^{1}$, Ali Burak Binboğa ${ }^{1}$ \\ ${ }^{I}$ Dr Ersin Arslan Training And Research Hospital}

Objective: This study is aimed to present the long-term results of the telescopic configuration created with a flow diverter device (FDD) and stent for fusiform intracranial aneurysms.

Materials and Methods: Between September 2016-September 2021, patients who underwent endovascular aneurysm treatment with the telescopic configuration using an FDD and stent were reviewed, retrospectively. O' KellyMarotta (OKM) grading scale was used to aneurysm occlusion rates. Patients' demographics, aneurysm features, complications, clinical and angiographic outcomes, long term results were noted.

Results: There were 11 patients ( 6 female, 5 male) with a median age of 56-year-old (min.-max.: 39-69-year-old). All patients had a fusiform aneurysm. $72.8 \%(\mathrm{n}=8)$ of the aneurysms were located ICA, $18.1 \%(n=2)$ basilar, $9.1 \%(n=1)$ MCA. The median aneurysm length was $21 \mathrm{~mm}$ (min.-max.: $17-30 \mathrm{~mm})$. The technical success rate was $100 \%$. There was no procedure-related complication. According to OKM grades, A3 was observed in 4 patients, A2 in 6 patients, and $\mathrm{B} 2$ in 1 patient, intraoperatively. The follow-up period was 30 months (min.-max.: 0-48 months). Total aneurysm occlusion was observed in $63.6 \%(n=7)$ of patients. Aneurysm remnant was observed in $27.2 \%(n=3)$ of patients 
without a size increase. The mortality rate was $9.1 \%(n=1)$. This patient experienced early acute stent thrombosis due to self-interrupting antiaggregant medication after hospital discharge. In other patients, modified Rankin scales were 1 or 2 that indicated good clinical outcomes.

Conclusion: Telescopic configuration with FDD and stent was a safe and effective approach for reconstructing a fusiform aneurysm.

Keywords: Telescopic stent, fusiform aneurysm, endovascular treatment.

Pediatric Neuroradiology

Ref No: 31

\section{Oral Presentation}

DIFFERENTIATION OF MEDULLOBLASTOMA MOLECULAR SUBTYPES WITH MULTIPARAMETRIC MRI FINDINGS INCLUDING MAGNETIC RESONANCE IMAGING-BASED TEXTURE ANALYSIS

Bülent Aslan ${ }^{1}$, Nuri Çagatay Çimşit ${ }^{1}$, Erhan Bıyıklı ${ }^{1}$, Tahsin Aybal $^{1}$, Gülnur Tokuç ${ }^{1}$, Süheyla Bozkurt ${ }^{1}$

${ }^{1}$ Marmara University School Of Medicine

Objective: The aim of our study was to differentiate medulloblastoma molecular subtypes with multiparametric MRI findings including magnetic resonance imaging-based texture analysis.

Materials and methods: Fifty-eight patients with preoperative MRI and histopathological diagnosis of medulloblastoma after surgery were included in our study. The patients were divided into two groups as SHH pathway active and group 3/group 4 medulloblastoma. Morphological findings in brain MRI, ADC measurements and texture analysis features of the lesions in both groups were compared.

Results: Thirty-two (55.2\%) of 58 medulloblastoma patients included in the study were SHH pathway, while the others were group 3-4 molecular subtype. Among the morphological findings, being out of midline or in the cerebellar hemisphere $(\mathrm{p}<0.001)$, peri-tumoral edema $(\mathrm{p}=0.041)$, macrocyst $(\mathrm{p}=0.001)$ and nodular involvement/lobulation $(\mathrm{p}=0.002)$, as well as heterogeneous contrast enhancement $(\mathrm{p}=0.002)$ 0.011 ) were statistically more common in SHH active tumors. The ratio of the solid part of the tumor to the thalamus in ADC measurements was statistically significantly lower in SHH tumors $(\mathrm{p}<0.001)$. When the threshold value for this ratio was determined as 0.855 , the sensitivity was $82.1 \%$ and the specificity was $92.3 \%$. As for texture analysis parameters, kurtosis $(p=0.023)$, SumOfSqs $(p=0.022)$ and
01-10-50-90\% percentile (respectively $\mathrm{p}=0.011 ; \mathrm{p}=0.001$; $\mathrm{p}=0.006 ; \mathrm{p}=0.013)$ values obtained from ADC images and kurtosis $(\mathrm{p}=0.041)$, SumOfSqs $(\mathrm{p}=0.005)$, SumVarnc $(\mathrm{p}=0.014)$, SumEntrp $(\mathrm{p}=0.032)$ values obtained from T1W images were statistically significant in differentiating $\mathrm{SHH}$ and group 3/ group 4 medulloblastoma.

Conclusion: The use of morphological MRI findings, ADC measurement, and texture analysis parameters provide useful diagnostic information in identifying medulloblastoma molecular subtypes.

Keywords: medulloblastoma, ADC measurement, texture analysis, brain MRI, Sonic hedgehog

\section{References:}

1. Pollack IF, Jakacki RI. Childhood brain tumors: Epidemiology, current management and future directions. Nat Rev Neurol. 2011;7(9):495-506. doi:10.1038/nrneurol.2011.110 2. Kool M, Korshunov A, Remke M, et al. Molecular subgroups of medulloblastoma: An international meta-analysis of transcriptome, genetic aberrations, and clinical data of WNT, SHH, Group 3, and Group 4 medulloblastomas. Acta Neuropathol. 2012;123(4):473-484. doi:10.1007/ s00401-012-0958-8

3. Northcott PA, Korshunov A, Witt H, et al. Medulloblastoma comprises four distinct molecular variants. J Clin Oncol. 2011;29(11):1408-1414. doi:10.1200/ JCO.2009.27.4324

Head-Neck Radiology

Ref No: 32

\section{Oral Presentation}

INTER-RATER RELIABILITY OF CHOLESTEATOMA LOCALIZATION WITH MRI GUIDED TEMPORAL BONE CT

Umut Perçem Orhan Söylemez ${ }^{1}$, Başak Atalay ${ }^{2}$, Nesrin Gündüz ${ }^{2}$

${ }^{1}$ Istanbul Goztepe Prof.dr. Suleyman Yalcin City Hospital

${ }^{2}$ Istanbul Medeniyet University Faculy Of Medicine

Objective: Non-echo planar diffusion weighted imaging(DWI) is very sensitive do detect even very small cholesteatomas. However, due to the lack of anatomical detail in diffusion imaging, temporal bone CT is definitely evaluated (1). This study aimed to evaluate the inter-rater reliability of detection of exact localization of cholesteatomas by using $\mathrm{CT}$ and MRI together.

Material and methods: University ethics committee approval was obtained this retrospective study 
(ID:2021/0496 ). The word 'cholesteatoma' was scanned in the radiological reports in the hospital archive. Patients with MRI confirmed cholesteatoma in four years period were included the study. Images with inadequate quality, patients don't have both CT and MRI and without cholesteatoma in the current evaluation were excluded. Primarily cholesteatoma confirmed from MRI, than the exact localization of the lesion was evaluated in thin section temporal bone CT by two independent radiologists. Localizations were described as; external acoustic canal, mastoid (air cell/ antrum/ cavity), periossicular (malleus/incus/ all), epitimpanium (medial/ lateral/superior), mesotimpanium, hypotimpanium, prussak space, pars tensa and pars flaccida. İnter-rater reliability assessed were based on the kappa coefficient $(\kappa)$, with $\kappa$ $\leq 0$ defined as no agreement, $0.01-0.20$ as none to slight, $0.21-0.40$ as fair, $0.41-0.60$ as moderate, $0.61-0.80$ as substantial, and 0.81-1.00 as almost perfect agreement.

Results: 89 patients (45 woman) were included. The age range was between 5 to 89 and the mean age was 39.07. Inter-rater reliabilites were moderate to almost perfect according to localization of cholesteatomas. ' $\kappa$ ' changed between 0.48 to 0.83 (Table 1 ).

Conclusion: In this study, inter-rater reliability in terms of localization of cholesteatoma was moderate to almost perfect. While the highest agreement was in the evaluation of mesotympanium, external acoustic canal and mastoid bone, the lowest agreement was found in the evaluation of the medial epitympanic recess. Surgical mapping is important for the successfull surgery of cholesteatomas. Especially when chronic otitis media presents, it is challenging to differentiate cholesteatoma from other densities (2). Non-echo planar DWI is very sensitive even for detecting very small cholesteatomas (3). CT is perfect for anatomic detail (1). Therefore, fusion imaging studies have come to the fore. Few studies with a small number of patients reported that fusion imaging is superior to evaluation with only CT or MRI alone (2) (4). In this study with a large patient cohort, we aimed to investigate how reliably we could detect cholesteatomas without using fusion imaging. The limitation of the study is that the localization of cholesteatomas were not compared with surgical results. In conclusion, our results revealed that without fusion imaging, the exact localization of cholesteatomas can be determined in most of the cases by combining CT and MRI.

Keywords: Cholesteatoma, Tomography, Magnetic Resonance Imaging, Otitis Media

\section{References:}

1. Gulati M, Gupta S, Prakash A, Garg A, Dixit R. HRCT imaging of acquired cholesteatoma: a pictorial review.
Insights Imaging. 2019 Oct 3;10(1):92. doi: 10.1186/s13244019-0782-y. PMID: 31578644; PMCID: PMC6775179.

2. Locketz GD, Li PM, Fischbein NJ, Holdsworth SJ, Blevins NH. Fusion of Computed Tomography and PROPELLER Diffusion-Weighted Magnetic Resonance Imaging for the Detection and Localization of Middle Ear Cholesteatoma. JAMA Otolaryngol Head Neck Surg. 2016 Oct.

3. Dudau C, Draper A, Gkagkanasiou M, Charles-Edwards G, Pai I, Connor S. Cholesteatoma: multishot echo-planar vs non echo-planar diffusion-weighted MRI for the prediction of middle ear and mastoid cholesteatoma. BJR Open. 2019 Jan 10;1(1):20180015. doi: 10.

4. Sharma SD, Hall A, Bartley AC, Bassett P, Singh A, Lingam RK. Surgical mapping of middle ear cholesteatoma with fusion of computed tomography and diffusion-weighted magnetic resonance images: Diagnostic performance and interobserver agreement. Int J Pedia.

Adult Neuroradiology

Ref No: 33

\section{Oral Presentation}

\section{RELATIONSHIP OF LIMBUS VERTEBRAE AND SCHMORL'S NODE}

Serife Leblebisatan ${ }^{1}$

${ }^{I}$ Adana City Training And Research Hospital, University of Health Sciences

Objective: Limbus Vertebrae (LV) and Schmorl's node (SN) are pathological conditions that can mimic each other and need to be differentiated $(1,2)$. In this study, the percentages of LV and SN and in which vertebral column they were most common were evaluated. Comparison was made in terms of genders and the frequency of coexistence in the same patient was evaluated whether they were predisposing to each other.

Materials and methods: Approval for this retrospective study was obtained from the institutional ethics committee. Patients who underwent all three MRI examinations of the cervical, thoracic and lumbar vertebrae on 1.5 and 3.0 Tesla MRI devices (Philips Ingenia, 2017, Best, Netherlands) between 01.06.2020-31.12.2020, were retrospectively evaluated. After excluding patients with trauma, operation, malignancy, and congenital anomalies, the presence and localization of LV and SN were determined in the remaining 500 patients.

Results: 209 male (41.8\%) and 291 female (58.2) patients were included in the study. The mean age was $42.1 \pm 18.4$. LV was detected in 90 patients (18\%) and SN in 204 patients (40.8\%). The number of patients with both LV and SN was $49(9.8 \%)$. LV was most common at the lumbar level and SN 
was most common at the thoracic level. The incidence of $\mathrm{SN}$ in the vertebral inferior plate was higher than in the LV $(p<0.001)$. When patients with and without LV were compared, the presence of SN was observed more frequently in patients with LV (Table 1). The frequency of $\mathrm{SN}(\mathrm{p}<0.001)$ and the presence of LV and $\mathrm{SN}$ together $(\mathrm{p}=0.021)$ were found to be higher in male patients than in females. The numbers of patients with single and multiple levels of LV and $\mathrm{SN}$ are shown in Table 2.

Conclusion: Disc herniation usually follows a horizontal course. However, herniation into the vertebral body in the vertical direction also occurs (3). It has two different forms. While the limbus vertebra (LV) develops at the vertebral corpus corner and early adolescence, Schmorl's node (SN) forms centrally and increases with age $(3,4)$. They occur when the disc extends into the bone from weak points in the end plate with axial loading (5). The exact cause of SN is unknown (3). However, the higher incidence of SN in individuals with LV compared to those without LV supports a common or related pathogenesis. In the literature, LV is reported at a single level in case reports (1). In our study, approximately one third of the patients with $\mathrm{LV}$ were found to have more than one level. SN has been reported in $38 \%$ to $75 \%$ of the population (6). However, it has also been suggested that the $10 \%$ to $16 \%$ rate is more realistic (7). In this study, the percentage of patients with SN was 40.8. Consistent with the literature, $\mathrm{SN}$ was more common in males $(6,7)$. Individuals who develop LV in early adolescence are at increased risk for developing $\mathrm{SN}$ in the future.

Keywords: Cervical vertebrae, thoracic vertebrae, lumbar vertebrae, magnetic resonance imaging.

\section{References:}

1- Sanal HT, Yilmaz S, Simsek I. Limbus vertebra. Arthritis Rheum. 2012 Dec;64(12):4011. doi: 10.1002/art.34630.

2- Graikos G, Gkoudina A, Tsakonas N, Christakis N. Limbus Vertebrae as Incidental Finding in a Patient With Acute Lower Back Pain Cureus. 2020 Sep; 12(9): e10658. doi: 10.7759/cureus. 10658

3- Mohty KM, Mandair D, Munroe B, Baldemor D. A Case of Persistent Low Back Pain in a Young Female Caused by a Trauma-Induced Schmorl's Node in the Lumbar Spine Five Vertebra. Cureus. 2017 Jul 21;9(7):e1502. doi: 10.7759/ cureus. 1502.

4- Wáng YXJ, Santiago FR, Deng M, Nogueira-Barbosa $\mathrm{MH}$. Identifying osteoporotic vertebral endplate and cortex fractures. Quant Imaging Med Surg. 2017 Oct;7(5):555-591. doi: 10.21037/qims.2017.10.05.

5- Huang PY, Yeh LR, Tzeng WS, Tsai MY, Shih TT, Pan HB, Chen CK. Imaging features of posterior limbus vertebrae. Clin Imaging. 2012 Nov-Dec;36(6):797-802. doi: 10.1016/j.clinimag.2012.01.031.

6- Abu-Ghanem S, Ohana N, Abu-Ghanem Y, Kittani M, Shelef I. Acute schmorl node in dorsal spine: an unusual cause of a sudden onset of severe back pain in a young female. Asian Spine J. 2013 Jun;7(2):131-5. doi: 10.4184/ asj.2013.7.2.131.

7- Paterakis KN, Brotis AG, Dardiotis E, Hadjigeorgiou GM, Karachalios T, Fountas KN, Karantanas A. Acute Schmorl's Node during Strenuous Monofin Swimming: A Case Report and Review of the Literature. Global Spine J. 2012 Sep;2(3):159-68. doi: 10.1055/s-0032-1307262. Epub 2012 Aug 24.

Pediatric Neuroradiology

Ref No: 34

\section{Oral Presentation}

\section{MR EVALUATION OF PINEAL GLAND VOLUME IN CHILDREN \\ $\underline{\text { Sabriye Gülçin Bozbeyoğlu }}^{1}$ \\ ${ }^{1}$ Medeniyet Üniversitesi Süleyman Yalçın Şehir Hastanesi}

Objective: The aim of this study is to determine the distribution of pineal gland volume according to age and gender, as well as the frequency of incidentally detected pineal cysts in children under 18 years of age.

Materials and methods: In this single-center retrospective study, brain MRI examinations of children between the ages of 1 month and 18 years old between May and October 2021 were evaluated after the approval of the local ethics committee. Maximum length $(\mathrm{L})$ and height $(\mathrm{H})$ were taken with sagittal 3D cube T1 $(1 \mathrm{~mm} 3)$ images taken from 1.5 tesla MR device (FOV 25, section thickness $1 \mathrm{~mm}$, TR 550, TE min). The volume was calculated $(0.52 \times \mathrm{LxHxW})$ by taking the width (W) from the axial T2 prop images taken with TR 5140,TE 89,FOV 24cm, 3mm section thickness.Statistical evaluation of the data performed with SPSS 21.0. The distribution of the data is evaluated with one sample Kolmogorov Smirnov test. Data with normal distribution evaluated with Student's t test and abnormally distributed data were evaluated with one-way ANOVA test. Data for continuous variables were given as mean \pm standard deviation. The change in pineal gland volume with age was evaluated with the correlation test. A value of $\mathrm{P}<0.05$ was considered statistically significant.

Results: A total of 380 patients, 222(58\%) female and $158(42 \%)$ male, had a mean age of $10.4 \pm 4.5$ years. The mean pineal gland volume was measured as $80.0 \pm 47.2 \mathrm{ml}$. The 
patients were divided into 0-5 age Group 1,6-10 age Group 2,11-15 age Group 3 and post-16 age group 4 (Table 1). Pineal gland volume in group- 1 was statistically significantly lower than the other groups $(\mathrm{p}=0.003)$. There was a significant difference between group- 1 and group- $2(\mathrm{p}=0.047)$ and between group- 1 and group- $3(\mathrm{p}=0.001)$.No significant difference was found when the other groups were compared with each other.(Table 2)Pineal gland cysts were detected in 44(\%11.6) patients. The pineal gland volume was measured as $156.4 \pm 75.7$ in $40 \%$ of these patients and $60 \%$ of them were girls, and it was found to be statistically significantly higher than those without cysts $(\mathrm{p}<0.001)$.Pineal gland volume was significantly higher in patients with cysts than in patients without cysts $(\mathrm{p}<0.001)($ table 3$)$. In patients without cysts, a weak positive correlation was found between pineal gland volumes and the age of the patients $(\mathrm{r}=0.171, \mathrm{p}=0.001)$.

Conclusion: In this study, we found that pineal gland volume increased with age, did not change according to gender, and gland size increased in the presence of pineal cyst. The mean pineal gland volume was measured as $80.0 \pm 47.2 \mathrm{ml}$ in children under 18 years of age. In conclusion, this study is the largest series of studies evaluating pineal gland volume with MRI in the pediatric population, and it has been shown that the size increases with increasing age and the presence of cysts

Keywords: pineal children

\section{References:}

1- Gray's anatomy. 40th edition. [Edinburgh]: Churchill Livingstone/Elsevier, 2008. ISBN:0443066841

2- Smith AB, Rushing EJ, Smirniotopoulos JG. From the archives of the AFIP: lesions of the pineal region: radiologic-pathologic correlation. Radiographics. 2010;30 (7): 2001-20.

3- Tien RD, Barkovich AJ, Edwards MSB. MR imaging of pineal tumors. AJNR Am J Neuroradiol 1990;11:557-565

4- Zee CS, Segall H, Apuzzo M, et al. MR imaging of pineal region neoplasms. J Assist Comput Tomogr 1991;15:56 - 63 5- Sumida M, Barkovich AJ, Newton TH. Development of the pineal gland: measurement with MR. AJNR Am J Neuroradiol 1996; 17: 233-6.

6- Lacroix-Boudhrioua V, Linglart A, Ancel PY, Falip C, Bougnères PF, Adamsbaum $\mathrm{C}$. Pineal cysts in children. Insights Imaging. 2011;2:671-678.

Head-Neck Radiology

Ref No: 35

\section{Oral Presentation}

CONTRIBUTION OF CONE BEAM CT TO EVALUATION OF FACIAL NERVE IN TRAUMATIC FACIAL PALSY

$\underline{\text { Ahmet Kursat Karaman }}^{1}$, Bora Korkmazer ${ }^{2}$, Emine Deniz Gözen ${ }^{3}$, Osman Kızılkılıç ${ }^{2}$

${ }^{1}$ Sureyyapasa Chest Diseases And Thoracic Surgery Training And Research Hospital

${ }^{2}$ Division Of Neuroradiology, Department Of Radiology, Istanbul University-cerrahpasa, Istanbul, Turkey;

${ }^{3}$ Department Of Otorhinolaryngology, Istanbul Universitycerrahpasa, Istanbul, Turkey

Objective: The facial nerve may be affected in $7-10 \%$ of post-traumatic temporal bone fractures. If the injured facial nerve is not treated promptly and effectively, permanent sequelae and facial deformity may develop. Therefore, rapid and accurate diagnosis is very important ${ }^{1,2}$. Although highresolution CT is the gold standard method in diagnosis, it may be insufficient to evaluate the tympanic segment of the facial nerve. Cone Beam CT provides an advantage in evaluating temporal bone structures and the course of the facial nerve by providing multiplanar high resolution images. In this study, we aimed to demonstrate the diagnostic contribution of Cone Beam CT in detecting post-traumatic facial nerve damage.

Materials and methods: Between January 2017 and June 2021, patients who underwent both temporal bone CT and Cone Beam CT examination with a preliminary diagnosis of traumatic facial paralysis were included in the study. Conventional temporal $\mathrm{CT}$ and Cone Beam CT images of all patients were evaluated retrospectively and independently of each other. Bone facial canal and all segments of the facial nerve were evaluated for pathological appearance. The fracture orientation in the temporal bone and the anatomical structures of the temporal bone affected by the fracture were also recorded.

Results: The mean age of 7 patients included in the study was $29.1 \pm 15.3$ and all of the cases were male. All cases were high-energy trauma patients and the most common etiologic cause was falling from height $(57,1 \%)$. Most of the patients $(5 / 7,71,4 \%)$ had right-sided facial paralysis and right temporal bone fracture. $42,9 \%$ of the temporal bone fractures were in the longitudinal orientation and the rest were in the transverse orientation. A fracture line was observed in the wall of the facial nerve canal in only 1 patient $(14,3 \%)$ in conventional temporal CT examination. On the other hand, facial nerve pathology was observed in $5(71,4 \%)$. patients in cone beam CT. Loss of integrity in the facial canal wall was observed in 3 of these 5 patients 
(Fig. 1,2), hematoma in the facial canal in 1 patient (Fig. 3), and edema in the facial nerve in 1 patient. Other accompanying findings were mastoid fracture $(57.1 \%)$, external auditory canal bone fracture $(42.9 \%)$, incudomalleolar dislocation $(14.3 \%)$.

Conclusion: Our study shows that Cone Beam CT can be useful in detecting facial nerve damage that cannot be detected in conventional temporal CT. High-resolution multiplanar images obtained in Cone beam CT in this indication can play a problem-solving role in diagnosis in traumatic patients.

Keywords: Cone-Beam CT, Facial Nerve Trauma, Temporal bone

\section{References:}

1. Vajpayee D, Mallick A, Mishra AK. Post Temporal Bone Fracture Facial Paralysis: Strategies in Decision Making and Analysis of Efficacy of Surgical Treatment. Indian J Otolaryngol Head Neck Surg [Internet]. 2018/04/19. 2018 Dec;70(4):566-71. Available from: https://pubmed.ncbi. nlm.nih.gov/30464917

2. Chang CY, Cass SP. Management of facial nerve injury due to temporal bone trauma. Am J Otol. 1999 Jan;20(1):96-114.

3. Zhang Z, Yin H, Wang Z, Li J, Lv H, Zhao P, et al. Imaging re-evaluation of the tympanic segment of the facial nerve canal using cone-beam computed tomography compared with multi-slice computed tomography. Eur Arch OtoRhino-Laryngology [Internet]. 2019;276(7):1933-41. Available from: https://doi.org/10.1007/s00405-019-05419-3

4. Hiraumi H, Suzuki R, Yamamoto N, Sakamoto T, Ito J. The sensitivity and accuracy of a cone beam CT in detecting the chorda tympani. Eur Arch Oto-Rhino-Laryngology [Internet]. 2016;273(4):873-7. Available from: https://doi. org/10.1007/s00405-015-3647-0

Head-Neck Radiology

Ref No: 36

\section{Oral Presentation}

CT CLASSIFICATION OF MAXILLOFACIAL TRAUMAS IN MOTORCYCLE AND CYCLIST ACCIDENTS Seydi Hamit Korkmaz ${ }^{1}$, Fatma Can ${ }^{1}$, Yüksel Pabuşcu ${ }^{1}$

${ }^{1}$ Manisa Celal Bayar University Radiology

Objective: We aimed to Multidetector computed tomography (CT) classification of maxillofacial traumas in motorcycle and cyclist accidents.
Materials and methods: A retrospective review of patient records and CT scans was performed. Data on age, gender, fracture type, anatomical region, and intracranial hemorrhage were reviewed.91 patient records were reviewed. $93.4 \%$ of 91 patients were male. The age range was 10-73 years (mean: 34.10).

Results: Nasal bone fracture was observed in $48.3 \%$ of 91 patients. This was followed by maxillary and orbital bone fractures (40.6\%-32.9\%). Bilateral displaced fractures $(61.3 \%)$ were the most common among nasal bone fractures. Intracranial hemorrhage was observed in $48.4 \%$ of 91 patients. The most common type of bleeding is Subarachnoid hemorrhage, which is seen in $65.9 \%$ of hemorrhages. A significant correlation was found between nasal, frontal, temporal and sphenoid bone fractures and bleeding. Frontal bone fractures increase bleeding 5.4 times, temporal bone fractures 10.9 times. There was no significant relationship between the type of fracture being displaced or non-displaced and intracranial bleeding.

Conclusion: Multidetector CT is the imaging modality of choice for the evaluation of fractures in maxillofacial trauma. Identification of fractures and accompanying complications, guides the planning of treatment.

Keywords: Injuries, Maxillofacial,Computed Tomography, Fracture

Head-Neck Radiology

Ref No: 37

\section{Oral Presentation}

\section{OTIC CAPSULE THICKNESS OF INCOMPLETE PARTITION ANOMALIES}

Safak Parlak $^{1}$, Yasin Yaraşır ${ }^{1}$, Ayça Akgöz Karaosmanoğlu ${ }^{1}$, Sevtap Arslan ${ }^{1}$, Levent Sennaroğlu ${ }^{2}$

${ }^{1}$ Hacettepe University, Department Of Radiology

${ }^{2}$ Hacettepe University, Department Of Otolaryngology

Objective: The otic capsule (osseous (bony) labyrinth) is the dense bone of the petrous temporal bone and surrounds the membranous labyrinth of the inner ear. The purpose of this study was to document the otic capsule thickness in a series of patients with incomplete partition anomalies.

Material and methods: A total of 176 ears of 87 patients with incomplete partition anomalies (25 ears with IP-1, 125 ears with IP-2, 26 ears with IP-3) and 320 ears of 160 patients with normal temporal bone findings were retrospectively examined. The otic capsule thickness was measured anterior to the cochlea, from the anterior aspect of the 
cochlear apex to the anterior cortical margin in all incomplete partition groups and compared to the control group. Kruskal Wallis test and Pairwise comparisons were used for comparison of otic capsule thickness in groups. Spearman correlation was used for correlations between otic capsule thickness and age and gender. The result was considered statistically significant when $\mathrm{p}<0.05$.

Results: Otic capsule thickness was statistically lower in patients with IP-3 (median:0.5 mm; min/max:0.3/0.9 mm) $(\mathrm{p}<0.001)$. Median values of otic capsule thickness in IP-1 (median:0.9 mm; min/max:0.2/2.0 mm), IP-2 (median:1.0 $\mathrm{mm} ; \mathrm{min} / \mathrm{max}: 0.3 / 2.0 \mathrm{~mm}$ ) were not different than controls (median:1.0 mm; min/max:0.3/2.1 mm). Otic capsule thickness showed negative correlation with age in all groups and it was statistically significant in IP- $1(\mathrm{p}=0.004)$. Otic capsule thickness was higher in men $(n=42)$ than women $(n=83)$ in IP-2 ( $\mathrm{p}=0.003)$.

Conclusion: Otic capsule thickness is lower in ears with IP-3 than ears with other incomplete partition anomalies and controls and supports a relationship between otic capsule maturation and gene deficiency.

Keywords: incomplete partition anomalies, otic capsule

\section{References:}

1. Sennaroglu L. Histopathology of inner ear malformations: Do we have enough evidence to explain pathophysiology? Cochlear Implants Int. 2016; 17(1):3-20.

2. Sennaroglu L, Saatci I. A new classification for cochleovestibular malformations. Laryngoscope. 2002;112(12):2230-41.

3. Song MH, Choi SY, Wu L, Oh SK, Lee HK, Lee DJ, et al. Pou3f4 deficiency causes defects in otic fibrocytes and stria vascularis by different mechanisms. Biochem Biophys Res Commun. 2011;404(1):528-33.

Adult Neuroradiology

Ref No: 41

\section{Oral Presentation}

INVESTIGATION OF GAMMA KNIFE RADIOSURGICAL TREATMENT EFFECT ON OPTIC PATHWAYS IN USING DIFFUSION TENSOR MRI

Merve YAZOL $^{1}$, Halil ÖZER ${ }^{1}$, Berrak BARUTÇU ASFUROĞLU $^{1}$, Gökhan KURT ${ }^{2}$, Hakan EMMEZ ${ }^{2}$, Ali Yusuf ÖNER ${ }^{1}$

${ }^{I}$ Gazi University Faculty Of Medicine, Department Of Radiology, Ankara-turkey
${ }^{2}$ Gazi University Faculty Of Medicine, Department of Neurosurgery, Ankara-turkey

Objective: To investigate DTI indices changes of the early radiation-induced effects on optic pathways that occur after GKRS for sellar-parasellar tumors.

Materials and methods: Twenty-five patients who received Gamma Knife stereotactic radiosurgery for sellar- parasellar tumors were included in the study. Each patient underwent MRI with T1WI, DTI, and T2WI before and at the 3 months after radiosurgery. The regions of interest (ROIs) were set on each optic nerve $(\mathrm{ON})$, anterior-central and posterior optic radiations (OR), and control localization. For each ROI, fractional anisotropy (FA), apparent diffusion coefficient (ADC) axial diffusivity (AD), radial diffusivity (RD), eigenvalues were calculated. Pre and post-radiosurgery differences of DTI values were statistically compared by using paired t-test.

Results: At 3 months after GKRS, bilateral optic nerves showed significantly lower FA values $(\mathrm{p}<0.05)$ and higher ADC, $\lambda 2, \lambda 3$, and $R D$ values $(p<0.05)$. The increase in $\mathrm{AD}$ for the left $\mathrm{ON}$ was significant. The anterior portion of bilateral optic radiations had a significant decrease in FA, increase in ADC, in addition, $\lambda 2$ and $\mathrm{RD}$ values for the left anterior portion of ORs significantly increased $(p<0.05)$. The percentage change in ADC, $\lambda 2$, and RD was statistically significantly higher in left optic nerves $(\mathrm{p}<0.05)$.

Conclusions: Optic pathways white matter injury can be induced by Gamma Knife radiosurgery targeted on sellar and parasellar tumors. The DTI parameters might be useful as a noninvasive biomarker for detecting early radiation-induced WM changes on optic pathways. The percentage change in $\mathrm{ADC}, \lambda 2$, and RD parameters was statistically significantly higher in left optic nerves.

Keywords: Gamma knife radiosurgery, Optic pathways, Diffusion tensor imaging, Sellar- parasellar tumor, Radiationinduced optic injury

\section{References:}

1. Fan, S.M., et al., Magnetic resonance diffusion tensor imaging study of rhesus optic nerve radiation injury caused by a single dose/fractionation scheme stereotactic radiosurgery at an early stage. Journal of Neuroradiology, 2016. 43(3): p. 207-213.

2. Monje, M.L., et al., Irradiation induces neural precursorcell dysfunction. Nature medicine, 2002. 8(9): p. 955-962.

3. Gavin, C.G. and H.I. Sabin, Stereotactic diffusion tensor imaging tractography for Gamma Knife radiosurgery. Journal of neurosurgery, 2016. 125(Supplement_1): p. 139-146. 
4. Wang, S., et al., Longitudinal diffusion tensor magnetic resonance imaging study of radiation-induced white matter damage in a rat model. Cancer research, 2009. 69(3): p. 1190-1198.

5. Song, S.-K., et al., Diffusion tensor imaging detects and differentiates axon and myelin degeneration in mouse optic nerve after retinal ischemia. Neuroimage, 2003. 20(3): p. 1714-1722.

Head-Neck Radiology

Ref No: 42

\section{Oral Presentation}

\section{DIFFERENTIATION OF METASTATIC AND BENIGN LYMPH NODES IN NASOPHARYNGEAL CANCER WITH MAGNETIC RESONANCE IMAGING TEX- TURE ANALYSIS \\ Halil Özer ${ }^{1}$, Nurullah Özdemir ${ }^{1}$, Abdussamet Batur ${ }^{1}$, Mehmet Sedat Durmaz ${ }^{1}$ \\ ${ }^{1}$ Department Of Radiology, Faculty Of Medicine, Selçuk University}

Objective: Magnetic resonance imaging (MRI) has an important place in local staging and diagnosis of lymph node metastasis in nasopharyngeal carcinoma (NPC). Texture analysis (TA) is a noninvasive method for assessing intratumoral characteristics and, as a result, can be used to diagnose malignancies. The purpose of this study is to look at the role of magnetic resonance imaging texture analysis in differentiating metastatic from non-metastatic lymph nodes in NPC.

Material and methods: Between January 2020 and October 2021, 14 nasopharyngeal cancer patients with malignant lymph nodes were included in the study. The radiological criteria were used to evaluate the malignant lymph nodes. Benign lymph nodes were used as control group. The texture features included first-order parameters, graylevel co-occurrence matrix (GLCM), and gray-level run length matrix (GLRLM) were compared between malignant and benign lymph nodes. Multivariate analysis was used to determine the independent predictor parameters. The receiver operating characteristic (ROC) analysis was used to determine the univariate and multivariate performance of texture parameters.

Results: The study included 11 male (78.6\%) and 3 female (21.4\%) patients with an average age of $52.86 \pm 7.43$ years (range, 42-66 years). The study examined 14 malignant lymph nodes and 14 benign lymph nodes.

\section{Texture Features}

There was no significant difference between the groups in the first order texture features ( $p>0.05$ ). Most of GLCM and GLRLM features in malign lymph nodes were significantly different $(\mathrm{p}<0.05)($ Table 1$)$.

\section{Multivariate Logistic Regression Analysis of Texture Parameters}

Among the texture parameters difference entropy, difference variance, maximum probability, gray level non uniformity, and gray level variancewere independent predictors of malign lymph nodes.

\section{ROC Analysis results}

The GLCM regression model and GLRLM regression model showed excellent diagnostic performance for detecting malign lymph nodes in nasopharyngeal carcinoma and the AUC values were 0.944 and 0.934 , respectively (Figure 2) (Table 2).

Conclusion: Recently, radiomics has been used for cancer detection, staging, and treatment response assessment. Current imaging methods are not sufficient to differentiate between metastatic and non-metastatic lymph nodes. The non-invasive image processing technique known as texture analysis has the ability to evaluate the spatial heterogeneity of the signal in tissues. This study demonstrates that textural features obtained from MRI images have diagnostic value in clinical practice, which can provide a non-invasive approach to distinguishing metastatic and non-metastatic neck lymph nodes of NPC. TA is useful in differentiating malignant lymph nodes from benign lymph nodes. In addition, multivariate regression model obtained by GLCM features and GLRLM features showed excellent diagnostic performance for detecting malign lymph nodes in nasopharyngeal carcinoma.

Keywords: Magnetic resonance imaging, Texture analysis, Nasopharyngeal carcinoma, Malignant lymph nodes

\section{References:}

1. Lee AW, Ng WT, Chan YH, Sze H, Chan C, Lam TH. The battle against nasopharyngeal cancer. Radiother Oncol. 2012;104(3):272-8.

2. Lan M, Huang Y, Chen CY, Han F, Wu SX, Tian L, et al. Prognostic Value of Cervical Nodal Necrosis in Nasopharyngeal Carcinoma: Analysis of 1800 Patients with Positive Cervical Nodal Metastasis at MR Imaging. Radiology. 2015;276(2):536-44.

De Cecco CN, Ganeshan B, Ciolina M, Rengo M, Meinel FG, Musio D, et al. Texture analysis as imaging biomarker of tumoral response to neoadjuvant chemoradiotherapy in 
rectal cancer patients studied with 3-T magnetic resonance. Invest Radiol. 2015;50(4):239-45.

3. Eliat PA, Olivié D, Saïkali S, Carsin B, Saint-Jalmes H, de Certaines JD. Can dynamic contrast-enhanced magnetic resonance imaging combined with texture analysis differentiate malignant glioneuronal tumors from other glioblastoma? Neurol Res Int. 2012;2012:195176.

4. Parikh J, Selmi M, Charles-Edwards G, Glendenning J, Ganeshan B, Verma H, et al. Changes in primary breast cancer heterogeneity may augment midtreatment MR imaging assessment of response to neoadjuvant chemotherapy. Radiology. 2014;272(1):100-12.

5. Park JH, Bae YJ, Choi BS, Jung YH, Jeong W-J, Kim H, et al. Texture Analysis of Multi-Shot Echo-Planar DiffusionWeighted Imaging in Head and Neck Squamous Cell Carcinoma: The Diagnostic Value for Nodal Metastasis. Journal of Clinical Medicine. 2019;8(11):1767.

Adult Neuroradiology

Ref No: 45

\section{Oral Presentation}

MAGNETIC RESONANCE IMAGING APPLICATIONS FOR EVALUATING TREATMENT RESPONSE AFTER RADIOSURGERY IN CEREBELLOPONTINE ANGLE TUMORS

Halil Özer ${ }^{1-3}$, Merve Yazol $^{1}$, Nesrin Erdoğan ${ }^{1}$, Hakan Emmez $^{2}$, Gökhan Kurt ${ }^{2}$, Ali Yusuf Öner ${ }^{1}$

${ }^{1}$ Department Of Radiology, Faculty Of Medicine, Gazi University

${ }^{2}$ Department Of Neurosurgery, Faculty Of Medicine, Gazi University

${ }^{3}$ Department Of Radiology, Faculty Of Medicine, Selçuk University

Objective: The outcome of radiosurgery for vestibular schwannoma is assessed by posttreatment measurement of tumor size. Unfortunately, these changes require a long time interval after radiosurgery. The purpose of this study is to determine the functional changes due to radiosurgery in patients with vestibular schwannoma with DCE-MRI and DTI at early stage and evaluate treatment response.

Material and methods: Twelve patients with vestibular schwannoma referred for stereotactic radiosurgery underwent MR examinations before, at the day after and at 3 months following the procedure with a $3 \mathrm{~T}$ scanner, using morphologic, DCE-MRI and DTI sequences. All data sets were transferred to a workstation for image evaluation. Perfusion and diffusion parameters were calculated by using commercial software programs on the workstation. Tumor volumes were measured from the morphologic sequences. Posttreatment tumor volumes, diffusion and perfusion parameters were compared with pretreatment scans.

Results: Mean tumors volume did not differ significantly throughout the study period (Table 1). After radiosurgery both DCE-MRI and DTI parameters demonstrated changes. Perfusion parameters remained stable the day after radiosurgery. Although there was no statistically difference found in the $k_{e p}$ values, a significant decrease in $K^{\text {trans }}, v_{e}$ and iAUC values were observed at 3 months post radiosurgery (Table 2). FA values decreased the day after radiosurgery and the reduction continued through the following 3 months. There was no difference in $\mathrm{ADC}, \mathrm{AD}$, and $\mathrm{RD}$ values at day 1 , and these values increased at 3 months followup (Table 3 ).

Conclusion: Functional imaging modalities such as DCEMRI and DTI have been shown to be biomarkers for predicting treatment response and long-term survival after chemoradiotherapy. DCE-MRI and DTI parameters differed 3 months after radiosurgery in our study. Furthermore, DTI parameters such as FA decreased on the first day following radiosurgery. DCE-MRI and DTI may show early functional changes after radiosurgery in vestibular schwannomas and may predict treatment response.

Keywords: DCE-MRI; DTI, Radiosurgery; Functional imaging; Oncology; Treatment response

\section{References:}

1. Battista RA. Gamma knife radiosurgery for vestibular schwannoma. Otolaryngologic Clinics of North America. 2009;42(4):635-54.

2. Abramson RG, Arlinghaus LR, Dula AN, Quarles CC, Stokes AM, Weis JA, et al. MR Imaging Biomarkers in Oncology Clinical Trials. Magnetic resonance imaging clinics of North America. 2016;24(1):11-29.

3. García-Figueiras R, Padhani AR, Baleato-González S. Therapy Monitoring with Functional and Molecular MR Imaging. Magnetic resonance imaging clinics of North America. 2016;24(1):261-88.

4. Almeida-Freitas DB, Pinho MC, Otaduy MC, Braga HF, Meira-Freitas D, da Costa Leite C. Assessment of irradiated brain metastases using dynamic contrast-enhanced magnetic resonance imaging. Neuroradiology. 2014;56(6):437-43.

5. Li K-L, Djoukhadar I, Zhu X, Zhao S, Lloyd S, McCabe $\mathrm{M}$, et al. Vascular biomarkers derived from dynamic contrast-enhanced MRI predict response of vestibular schwannoma to antiangiogenic therapy in type 2 neurofibromatosis. Neuro-oncology. 2015:nov168.Lin Y-C, Wang C-C, Wai Y, 6. Wan Y-L, Ng S-6. H, Chen Y-L, et al. Significant temporal evolution of diffusion anisotropy for evaluating early response to radiosurgery in patients with vestibular 
schwannoma: findings from functional diffusion maps. American Journal of Neuroradiology. 2010;31(2):269-74.

Pediatric Neuroradiololgy

Ref No: 48

\section{Oral Presentation}

EVALUATION OF THE PITUITARY VOLUME IN THE DIAGNOSIS OF IDIOPATHIC CENTRAL PRECOCIOUS PUBERTY: AN MRI STUDY

Nurdan Göcgü̈n ${ }^{1}$, Türkan İkizceli ${ }^{1}$

${ }^{1}$ University Of Health Sciences, Haseki Training And Research Hospital

${ }^{2}$ University Of Health Sciences, Haseki Training And Research Hospital

Objective: Precocious puberty is defined by the development of sexual characters before the age of 8 years in girls $(1,2)$. It is seen ten times more frequently in girls than in boys, and its prevalence is $0.2 \%$ (3-5). The aim of our study is to evaluate the contribution of pituitary volume and shapes on magnetic resonance imaging (MRI) findings in the diagnosis of idiopathic central precocious puberty, whose diagnosis is mostly made with clinical and laboratory findings.

Materials and methods: All pituitary MRIs obtained between January 2015 and May 2021 were retrospectively evaluated. Pituitary MRI images were obtained with a $1.5 \mathrm{~T}$ MRI (SIEMENS SOLA). 38 patients diagnosed with central precocious puberty based on clinical and laboratory findings were included in the study. 38 patients of thin-section contrast-enhanced cranial MRIs were included in the study as a control group. Cases with a prediagnosis of genetic or acquired disease in the hypothalamus and pituitary, mass, male gender, girls over 8 years of age, and cases that could not be evaluated due to motion artifact were excluded from the study. The study was approved by the ethics committee Pituitary volume by measuring the length, height, width of the pituitary was calculated. Pituitary gland length and height were measured from the midsagittal level where the infindibular stalk is observed. The pituitary shape was divided into three groups according to the upper contour based on Elster's classification (6). Concave upper contour is accepted as Group 1, flat contour group 2, and convex contour group 3. Data were analyzed using SPSS version 20.0 (IBM Corp, Armonk, NY, USA) statistics. The normality of the distribution of continuous variables was evaluated with the Kolmogorov-Smirnov test. ROC curves were obtained and calculated sensitivity and specificity.
Results: The age range of 38 female cases in the study group was 5-8 years (mean 7.3 \pm 0.9 years); In the control group, the age range was $2-8$ years (mean $5.3 \pm 1.8$ years). Pituitary gland height (h), length (L), width (W) and volume (V) were summarized in table 1 . In cases with pituitary gland shape precocious puberty, 26\% $(\mathrm{n}=10)$ group $1,69 \%(\mathrm{n}=26)$ group $2,5 \%(n=2)$ group 3 ; In the control group, $75 \%(n=28)$ group 1 and $25 \%(n=10)$ group 2 were present (Table 2$)$. The pituitary gland volume and contour measurements were found to be statistically significant among the patients and the control group.

Conclusion: Pituitary gland measurements obtained with magnetic resonance imaging in patients with pre-diagnosis of precocious puberty and the shape of the upper contour may be important parameters that can be used in the diagnosis of the disease. Thin-section pituitary imaging is essential for these patients not only to exclude the mass but also to measure the pituitary volume and contour.

Keywords: idiopathic central precocious puberty, children, magnetic resonance imaging, pediatric neuroradiology, hypophysis

\section{References:}

1. Partsch CJ, Heger S, Sippell WG. Management and outcome of central precocious puberty. Clin Endocrinol. 2002;56(2):129-148.

2. Brito VN, Latronico AC, Arnhold IJ, Mendonca BB. Update on the etiology, diagnosis and therapeutic management of sexual precocity. Arquivos brasileiros de endocrinologia e metabologia. 2008;52(1):18-31.

3. Teilmann G, Pedersen CB, Jensen TK, Skakkebaek NE, Juul A. Prevalence and incidence of precocious pubertal development in Denmark: an epidemiologic study based on national registries. Pediatrics. 2005;116(6):1323-1328.

4. De Sanctis V, Corrias A, Rizzo V, Bertelloni S, Urso L, Galluzzi F, et al. Etiology of central precocious puberty in males: the results of the Italian Study Group for Physiopathology of Puberty. J Pediatr Endocrinol Metab 2000; 13:687-693.

5. Chilton LA, Dorst JP, Garn SM. The volume of the Sella turcica in children: new standards. AJR AmJ Roentgenol. 1983;140(4):797-801.

6. Elster AD, Chen MY, Williams DW 3rd, Key LL. Pituitary gland: MRI imaging of physiologic hypertrophy in adolescence. radiology. 1990;174(3 Mon 1):681

Pediatric Neuroradiology

Ref No: 49 


\section{Oral Presentation}

\section{A NEW RADIOLOGICAL SIGN FOR CHIARI MAL- FORMATION TYPE 2: 'THE UFO SIGN"}

Ömer Bağcılar ${ }^{1}$, Ahmet Üstündağ $\breve{g}^{2}$, Osman Kızılkılıç²

${ }^{1}$ Silivri State Hospital. Radiology Department. Istanbul

${ }^{2}$ Istanbul University-cerrahpasa Cerrahpasa Medical Faculty Radiology Department Istanbul

Objective: Chiari malformation type $2(\mathrm{C} 2 \mathrm{M})$ is a complex developmental anomaly which mainly affects posterior fossa. We aim to describe a new radiological sign that may increase the memorability of posterior fossa changes of $\mathrm{C} 2 \mathrm{M}$ and also to investigate the interobserver reliability. Chiari malformation type $2(\mathrm{C} 2 \mathrm{M})$ is a complex developmental anomaly characterized by a small posterior fossa with low lying tentorial attachment, protrusion of the cerebellar vermis and brainstem below the plane of the enlarged foramen magnum. The cause of this malformation has been widely debated and the most accepted theory, proposed by McLone and Knepper ${ }^{1}$ in 1989 is based on myelomeningocele which is almost invariably associated with $\mathrm{C} 2 \mathrm{M}$. It is suggested that during the embryonic period, the persistent leakage of cerebrospinal fluid through a faulty neural tube prevents physiological distension of embryonic ventricular system. Decreased inductive pressure for calvarium results lowvolumed posterior fossa which has been suggested as the cause of constrained posterior fossa contents. Marin-Padilla and Marin-Padilla ${ }^{2}$ described in their occipital bone dysplasia theory that in $\mathrm{C} 2 \mathrm{M}$, foramen magnum is increased in size, posterior fossa length is reduced and height is increased. Consequently, reduced volume and disrupted architecture are responsible for pathological MRI signs of posterior fossa in $\mathrm{C} 2 \mathrm{M}$. Definitive features of $\mathrm{C} 2 \mathrm{M}$ which can be seen best on axial, sagittal or coronal plains are shown well in an interobserver reliability study. ${ }^{3}$ We aim to describe a new radiological sign called "The UFO Sign" which can be seen on coronal plane and also to investigate the interobserver reliability. UFO(unidentified flying object) is observed in the sky that is not readily identified and that term is used for lenticular shaped probably extraterrestrial originated spacecraft. In C2M, downward displacement of the attachment of the tentorium and dysplastic features of occipital bone discussed above contribute low posterior cranial fossa and cerebellar hemispheres takes elliptical, saucer shape which is similar with the UFO sightings flying saucers in the coronal plain. In addition to this, herniated cerebellar vermis and/or tonsils and upward herniation of cerebellum mimics the Command Center of the UFO. Radiological appearance discussed above is shown on figures 1 and 2 .

Materials and methods: Images of 15 patients with radiological suspicion of Chiari malformation type 2 with open spinal dysraphism who were presumed to have Chiari II malformation were included in this study. In addition, 15 patients with Chiari malformation type 1 were also included to reduce context bias.

Results: Coronal T2 weighted images were reviewed consecutively and independently by a senior radiology resident (A.U.) and a junior radiologist (O.B).(Fig 3) The 'present' and 'absent' ratings were tallied up per observer for the UFO sign. A Cohen's kappa test was run to test the agreement between two observers' ratings (UFO sign present/absent) using the Scipy library of Python programming language. The Cohen's kappa test provided a $k$ value of 0.45 , equating to a moderate agreement between the observers. The sensitivity and specificity of the UFO sign were calculated as 0,6 and 0,9 , respectively.

Conclusion: We describe a new radiological sign with moderate sensitivity, moderate agreement, and high specificity, which can be seen on coronal images of $\mathrm{C} 2 \mathrm{M}$ patients.

Keywords: Chiari malformation type 2, Spinal Dysraphism, Cerebellum

Head-Neck Radiology

Ref No: 52

\section{Oral Presentation}

SUCCESS OF KEROS CLASSIFICATION IN PARANASAL SINUS CT WITH DEEP LEARNING METHOD

Ahmet Dursun ${ }^{2}$, Veysel Atilla Ylldız ${ }^{1}$, Kenan Öztürk ${ }^{2}$, Fatih Ahmet Şenel $^{3}$

${ }^{1}$ Suleyman Demirel University Faculty Of Medicine Hospital, Department Of Radiology

${ }^{2}$ Suleyman Demirel University Faculty Of Medicine, Department Of Anatomy

${ }^{3}$ Suleyman Demirel University, Faculty Of Engineering, Department Of Computer Engineering, Department Of Computer Software

Objective: Detection of anatomical variations in depth of the olfactory fossa is important for prevention of complications in paranasal region surgery [1]. Keros divided depth of the olfactory fossa into three according to the length of the Lateral Lamella of Lamina Cribrosa (LCLL) [2]. In our study, we aimed to evaluate Keros classification with convolutional neural networks (CNN) on PNS-CT (Paranasal Sinus Computed Tomography) images and to determine the success rate of CNN in Keros classification.

Materials and methods: After the approval of Ethics Committee (Date: 05.06.2020 Decision no: 133), PNS-CT images of a total of 157 (77 men, 80 women) patients aged 18-90 
years were retrospectively analyzed. The coronal plane at which both infraorbital foramen were first seen was used for morphology of LCLL. The medial point (MEP) of the ethmoid roof was determined. The lowest point where the lamina cribrosa (LC) joins with LCLL was determined. The perpendicular distances from the MEP and LC reference points to the horizontal line connecting the infraorbital foramen were measured and named as the MEP and LC height (Figure a) [3]. The difference between them is the height of the LCLL, according to Keros [1] type I 1-3.99 mm, type II 4-6.99 mm, and type III 7-16 mm (Figure b-c-d). Images were divided into right and left olfactory fossae, with a plane passing through the middle of the crista galli. A total of 314 keros-classified olfactory fossa images were obtained, 64 of which were type 1,163 were type 2 , and 87 were type 3 . In deep learning method, CNN structure was used to extract feature maps from raw images. All studies were performed using Python programming language version 3.6 and Keras Deep Learning Library. Rotation, shearing, zooming, horizontal and vertical flip methods of 314 keros-classified PNS$\mathrm{CT}$ images were performed using the ImageDataGenerator tool in the Keras library. $85 \%$ of the data set used in the deep Learning process was reserved for training and $15 \%$ for testing. The training of the developed model was continued for 200 iterations. The suggested model was trained on Google Colab's Tesla graphics processing unit (GPU) with using Keras.Sensitivity/recall, precision, F1-score, and accuracy metrics were used as performance metrics and how they were calculated in equations $1,2,3$, and 4,respectively, is shown.In Table 1 the definitions required for performance metrics are given.

Results: In experimental studies, the most successful result was found as Accuracy metric 0.85 . Progression of the Loss function and Accuracy value through iterations during the training phase is shown in figure e. Metrics obtained as a result of the testing process of the developed model are given in Table 2. Confusion matrix is given in Figure f. Considering the tables in our study, it is understood that the Keros classification process can be done with $85 \%$ success rate.

Conclusion: There have been studies that classify skin cancer [4], predict cardiovascular risk factors [5], determine bone age and predict gender [6] using computational models using machine learning and especially deep learning. In the literature, we have not come across a study on Keros classification using deep learning method until now. Keros classification gives different results in different ethnic groups. Thanks to success rate we have achieved with this method, complications that may develop secondary to surgery can be prevented with high accuracy.
Keywords: Keywords: Olfactor fossa, Keros, Cribriform plate, Deep learning, Computed tomography

\section{References:}

1- Keros P. On the practical value of differences in the level of the lamina cribrosa of the ethmoid. Z Laryngol Rhinol Otol 1962; 41:809-813.

2- Ahmet KARA, Elden, H., GÜVEN, M., Yilmaz, M. S., \& Demir, D. (2018). Keros Classification and Evaluation of Cribriform Plate Depth Asymmetry with Paranasal Sinus Computed Tomography Examinations. Sakarya Medical Journal, 8(2), 352-358.

3- Gugapriya, T. S., \& Kumar, N. V. (2020). An Analysis of Configuration of Lateral Lamella of Cribriform Plate of Ethmoid: A Computed Tomographic Study. Journal of Krishna Institute of Medical Sciences (JKIMSU), 9(3).

4- Esteva A, Kuprel B, Novoa RA, Ko J, Swetter SM, Blau HM, Thrun S (2017) Dermatologist-level classification of skin cancer with deep neural networks (slides). Nature 542:115-118. https://doi.org/10.1038/nature21056

5- Poplin R, Varadarajan A V., Blumer K, Liu Y, McConnell M V., Corrado GS, Peng L, Webster DR (2018) Prediction of cardiovascular risk factors from retinal fundus photographs via deep learning. Nat Biomed Eng 2:158-164. https://doi. org/10.1038/s41551-018-0195-0

6- Li Y, Huang Z, Dong X, Liang W, Xue H, Zhang L, Zhang Y, Deng Z (2019) Forensic age estimation for pelvic X-ray images using deep learning. Eur Radiol 29:2322-2329. https://doi.org/10.1007/s00330-018-5791-6

Interventional Radiology

Ref No: 55

\section{Oral Presentation}

\section{INITIAL EXPERIENCE WITH LVIS ECO STENTS} Enes Özlük ${ }^{1}$, Civan Işlak ${ }^{2}$, Osman Kızılkılıç ${ }^{2}$, Naci Koçer ${ }^{2}$, Murat Velioğlu ${ }^{3}$

${ }^{1}$ İstanbul Galata University Vocational School Medical Imaging Techniques; Acrbadem Atakent Hospital

${ }^{2}$ Istanbul University-cerrahpaşa Medical School Radiology Department

${ }^{3}$ Istanbul Fatih Sultan Mehmet Training And Research Hospital Radiology Department

Objective: In this report we present 20 aneurysm cases which were treated with LVIS Evo stent and early term follow-ups.

Materials and methods: 14 patients were treated with Y stent asisted coiling. 
Results: One patient treated with only Y stenting without coiling. The rest of cases treated with stent asisted coiling.

Conclusion: LVIS Evo stent is a feasbile, self expandible, low profile stent system that can be used for aneurysm treatment especially during Y stenting.

Keywords: Aneurysm, stent, coil, embolisation, Y stent assisted coiling

\section{References:}

1. Akgul, E., Aksungur, E., Balli, T., Onan, B., Yilmaz, D. M., Bicakci, S., \& Erman, T. (2011). Y-stent-assisted coil embolization of wide-neck intracranial aneurysms. A single center experience. Interventional Neuroradiology : Journal of Peritherapeutic Neuroradiology, Surgical Procedures and Related Neurosciences, 17(1), 36-48. http://doi. org/10.1177/159101991101700107

2. Aydin, K., Men, S., Barburoglu, M., Sencer, S., \& Akpek, S. (2018). Initial and Long-Term Outcomes of Complex Bifurcation Aneurysms Treated by Y-Stent-Assisted Coiling with Low-Profile Braided Stents. AJNR. American Journal of Neuroradiology, 39(12), 2284-2290. http://doi. org/10.3174/ajnr.A5869

3. Cagnazzo, F., Limbucci, N., Nappini, S., Renieri, L., Rosi, A., Laiso, A., et al. (2019). Y-Stent-Assisted Coiling of Wide-Neck Bifurcation Intracranial Aneurysms: A Meta-Analysis. AJNR. American Journal of Neuroradiology, 40(1), 122-128. http://doi.org/10.3174/ajnr.A5900

4. Cekirge, H. S., Yavuz, K., Geyik, S., \& Saatci, I. (2011). A novel "Y" stent flow diversion technique for the endovascular treatment of bifurcation aneurysms without endosaccular coiling. AJNR. American Journal of Neuroradiology, 32(7), 1262-1268. http://doi.org/10.3174/ajnr.A2475

Adult Neuroradiology

Ref No: 56

\section{Poster Presentation}

\section{A RARE CASE REPORT OF HYPERTROPHIC OLI- VARY NUCLEUS DEVELOPMENT}

Enes Özlük ${ }^{1}$, Yavuz Bekmezci ${ }^{2}$, Murat $\mathrm{Aksu}^{2}$

${ }^{1}$ İstanbul Galata University Vocational School Medical Imaging Techniques; Acıbadem Atakent Hospital Radiology Department

${ }^{2}$ Acıbadem Mehmet Ali Aydinlar University Faculty Of Medicine, Neurology; Acıbadem Atakent Hospital Neurology

Department

Objective: Hypertrophic Olivary Degeneration is a rare form of transsynaptic degeneration and is the only type of degeneration that presents with hypertrophy rather than atrophy. It presents clinically with palatal myoclonus, ocular myoclonus and tremor.

Case Presentation: A 66-year-old female patient applied with the complaints of dizziness and imbalance that started 20 days before the admission. In neurological examination, consciousness was clear, cooperative and oriented, speech and comprehension were normal. There was neither nuchal rigidity nor meningeal irritation findings. Cranial nerve examination showed nystagmus striking the right gaze direction, muscle strength examination was complete. She was not able to walk due to ataxia.There was no metabolic and infectious pathology in the biochemistry examination, the SARS COV-2 antigen test was negative. Cranial MR imaging revealed an expansile lesion which was hyperintense on T2-FLAIR examination located at the left mesencephalopontine region, posteriorly adjacent to the 4 th ventricle. In the perfusion MR examination, increased perfusion was observed in the global and relative CBV maps compared to its symmetry. In the spectral analysis, a decreased ratio of NAA was detected in the non-enhancing region of the lesion compared to its symmetry. In the light of all these findings, the lesion was might to be a glial tumor containing high-grade areas. In cerebrospinal fluid examination (CSF), protein level was slightly elevated than to serum $(51 \mathrm{mg} / \mathrm{dL}>45 \mathrm{mg} / \mathrm{dL})$ and CSF IgG level was higher than blood $(48.4 \mathrm{mg} / \mathrm{L}>34 \mathrm{mg} / \mathrm{L})$. CSF paraneoplastic panel and cytopathologic evaluation were normal. Oligoclonal band was negative. Dexamethasone $4 \mathrm{mg} /$ day was started for the patient and the patient's complaints returned to normal at the follow-up. Control contrast-enhanced cranial MR examination at the $2^{\text {nd }}$ month showed that the lesion regressed almost completely. There was no enhancement. There was a newly slight T2-FLAIR signal intensity increase at medulla oblangata olivary on the rigth side. Dexamethasone treatment was continued. No change was observed in the control imaging and clinical picture performed at the 3rd month. Control imaging performed at the 7th month, the expansion and contrast enhancement of the lesion regressed almost completely over time with lineer haemorrhagic sequela on SWI, slight expansile appearance and signal increase developed at the right inferior olivary nucleus of medulla oblongata. This was interpreted in favor of hypertrophic olivary degeneration secondary to involvement of the left dentatorubral tracts.

Conclusion: It is known that hypertrophic olivary degeneration clinically presents with palatal myoclonus, ocular myoclonus and tremor due to involving the Guillain-Mollaret triangle. In our patient, the clinical picture presented with ataxia and the patient benefited from corticosteroid treatment. MRI follow-ups performed for mesencephalopontine junctional lesion revealed developement of the contralateral anterior medullary hyperintense lesion due to dentatorubral 
tractus degeneration compatible with hypertrophic olivary degeneration in a 5-month follow-up.

Keywords: Hypertrophic Olivary Degeneration, MR imaging

\section{References:}

1- Goyal M, Versnick E, Tuite P: Hypertrophic olivary degeneration: metaanalysis of the temporal evolution of M R findings. AJNR Am J Neuroradiol. 2000 Jun-Jul; 21(6):1073-7.

2- Wang H, Wang Y, Wang R, Li Y, Wang P, Li J, Du J. Hypertrophic olivary degeneration: A comprehensive review focusing on etiology. Brain Res. 2019 Sep 1;1718:53-63. doi: 10.1016/j.brainres.2019.04.024. Epub 2019 Apr 23. PMID: 31026459.

3- Onen MR, Moore K, Cikla U, Ucer M, Schmidt B, Field AS, Baskaya MK. Hypertrophic Olivary Degeneration: Neurosurgical Perspective and Literature Review. World Neurosurg. 2018 Apr;112:e763-e771. doi: 10.1016/j. wneu.2018.01.150. Epub 2018 Jan 31. PMID: 29382617.

Adult Neuroradiology

Ref No: 58

\section{Poster Presentation}

\section{CASE REPORT OF CREUTZFELDT-JAKOB DISEASE PRESENTING WITH VASCULAR INVOLVEMENT \\ Yavuz Bekmezci ${ }^{1}$, Enes Özlük ${ }^{2}$, Murat Aksu ${ }^{1}$ \\ ${ }^{1}$ Acıbadem Mehmet Ali Aydınlar University Faculty Of Med- icine Neurology Department; Acıbadem Atakent Hospital Neurology Department \\ ${ }^{2}$ Istanbul Galata University Vocational School Medical Imaging Techniques; Acıbadem Atakent Hospital Radiol- ogy Department}

Objective: Creutzfeldt-Jakob disease is a disease with progressive cognitive decline. Its presentation with ischemia and/or vasculitic involvement in the brain is a rare condition.

Case presentation: 65 -year-old male patient presented with memory problems and confusional state that started about 1 month ago followed up due to the diagnosis of stroke and drugresistant epilepsy. On physical examination, body temperature, pulse and blood pressure was normal. He was tachypneic and had wheezing.Cardiovascular system and gastrointestinal system examinations were within normal limits. In the neurological examination, he was unconscious and had generalized tonic-clonic seizures. After his epileptic seizure activity ended, he was intubated and transferred to the ICU, and Midazolam and Phenobarbital perfusion was started. There was no metabolic and infectious pathology in the biochemistry examination and the SARS COV-2 antigen test was negative. Thorax computerised tomography examination was normal. In the cranial diffusion MR examination, there was diffusion restriction consistent with ischemia in left caudate nucleus and basal ganglia and both parietotemporaal cortical areas. In EEG examination; Synchronous paroxysms of multiple spikes and spikes with a duration of about 0.5 seconds and burst-suppression pattern after each paroxysm were observed. After IV Diazepam administration, epileptic activity was suppressed, but periodic burst-suppression pattern continued. Levetiracetam 3x1000mg and diphenyl hydantoin $2 \times 125 \mathrm{mg}$ treatment was started. In the lumbar puncture, cerebrospinal fluid (CSF) was clear, pressure was normal. CSF protein and glucose levels were normal. There were no cells. Neither viral nor bacterial agents could be produced in CSF examination. 14-3-3 protein was detected in CSF. Because the GTC epileptic seizure continued in the follow-up, valproate $2 \times 750 \mathrm{mg}$ and lacosamide $2 \times 100 \mathrm{mg}$ treatment was added to the existing levatiracetam and diphenyl hydantoin treatment. But despite this, it was observed that the patient's epileptic seizures continued intermittently. The patient did not respond to the cardiopulmonary recussitation due to sudden asystole in the 3rd week of his follow-up in the ICU and he was exitus accepted.

Conclusion: Confusional state and unstoppable epileptic seizures may be symptoms of many diseases, as well as a symptom of Creutzfeldt-Jakob disease. Ischemic-appearing lesions initially suggested acute ischemia in our case, but no pathology indicating cardioembolic origin was detected in the patient. Creutzfeldt-Jakob disease should also be considered as one of the possible etiological causes in the presence of confusional state, epileptic seizure and cortical diffusion restriction.

Keywords: Creutzfeldt-Jakob Disease, MR imaging, Diffusion restriction

\section{References:}

1- Sharma DK, Boggild M, van Heuven AW, White RP. Creutzfeldt-Jakob Disease Presenting as Stroke: A Case Report and Systematic Literature Review. Neurologist. 2017 Mar;22(2):48-53. doi: 10.1097/NRL.0000000000000107. PMID: 28248914.

2- Caobelli F, Cobelli M, Pizzocaro C, Pavia M, Magnaldi $\mathrm{S}$, Guerra UP. The role of neuroimaging in evaluating patients affected by Creutzfeldt-Jakob disease: a systematic review of the literature. J Neuroimaging. 2015 JanFeb;25(1):2-13. doi: 10.1111/jon.12098. Epub 2014 Mar 5. PMID: 24593302.

3- Park HY, Kim M, Suh CH, Kim SY, Shim WH, Kim SJ. Diagnostic value of diffusion-weighted brain magnetic resonance imaging in patients with sporadic Creutzfeldt-Jakob 
disease: a systematic review and meta-analysis. Eur Radiol. 2021 Dec;31(12):9073-9085. doi: 10.1007/s00330-02108031-4. Epub 2021 May 12. PMID: 33982159.

Adult Radiology

Ref No: 60

\section{Oral Presentation}

EVALUATION OF CORPUS CALLOSUM, OPTIC AND OLFACTORY NERVE SIZES WITH MRI IN MS PATIENTS

Sena Ünal ${ }^{1}$, Elif Peker ${ }^{1}$

${ }^{1}$ Ankara University School Of Medicine, Radiology

Department

Objective: Multiple sclerosis (MS) is a demyelinating disease affecting central nervous system. MS can lead atrophic changes in corpus callosum and optic nerves and may cause olfactory disfunction. The aim of this study is to evaluate the changes in corpus callosum sizes and optic and olfactory nerve diameters in MS patients.

Methods and materials: 46 MS patients examined with brain MRI between 2011 and 2021 were evaluated retrospectively. 10 patients without contrast-enhanced and thin slice images were excluded from the study. Control group consisted 36 patients who did not have any demyelinating disease or intraaxial brain tumor and examined with brain MRI for other reasons. In all MS patients and in control group intraorbital segment diameters of optic nerves were measured on axial $\mathrm{T} 2$ weighted images. Olfactory nerve diameters were measured on coronal T2 weighted images. Optic chiasma's anteroposterior (AP) length was measured on thin sliced axial postcontrast $\mathrm{T} 1$ weighted images. AP lengths of the corpus callosum, genu and splenium, height of the body and the corpus callosum area on midsagittal plane were measured on thin sliced sagittal postcontrast T1 weighted images. Corpus callosum index was calculated by dividing the sum of the AP length of the genu, the AP length of the splenium and the height of the body by the AP length of the corpus callosum.

Results: Comparing MS patients and control group there were no statistically significant differences for optic and olfactory nerve diameters. The height of the body, the length of the genu and the splenium, midsagittal area of corpus callosum and corpus callosum index were significantly lower in MS patients $(\mathrm{p}<0,05)$. Among the corpus callosum measurements the height of the body had the largest value of area under the curve. For differentiating MS patients and control group, when $5.05 \mathrm{~mm}$ was accepted as cut-off value for body height the sensitivity was $64 \%$ and the specificity was $72 \%$. When the cut-off value for corpus callosum index was accepted as 0,38 , the sensitivity and the specificity was $72 \%$ and $64 \%$, respectively. For corpus callosum midsagittal area when the cut-off value accepted as $576 \mathrm{~mm}^{2}$ the sensitivity and the specificity was $69 \%$.

Conclusion: In MS patients demyelination and axonal injury of corpus callosum can be seen and can lead to disability (1). In several studies it was reported that corpus callosum area and corpus callosum index can be used as a indicator of cognitive disability $(1,2)$. In this study the height of the corpus callosum, midsagittal area of the corpus callosum and the corpus callosum index were lower in MS patients and this was consistent with the literature. In some studies optic nerve atrophy and olfactory disfunction were reported in MS patients $(3,4)$. In this study there were no significant differences for optic and olfactory nerve diameters between MS patiens and control group.

Keywords: MS, corpus callosum, optic nerve, olfactory nerve, MRI

\section{References:}

1. Ozturk A, Smith SA, Gordon-Lipkin EM et al. MRI of the Corpus Callosum in Multiple Sclerosis: Association with Disability. Mult Scler. 2010; 16:166-177.

2. Granberg T, Bergendal G, Shams S et al. MRI-Defined Corpus Callosal Atrophy in Multiple Sclerosis: A Comparison of Volumetric Measurements, Corpus Callosum Area and Index. J Neuroimaging. 2015; 25:996-1001.

3. Chung MS, Choi WR, Jeong HY, Lee JH, Kim JH. MR Imaging-Based Evaluations of Olfactory Bulb Atrophy in Patients with Olfactory Dysfunction. Am J Neuroradiol. 2018; 39:532-537.

4. Lucassen EB, Turel A, Knehans A, Huang X, Eslinger P. Olfactory dysfunction in Multiple Sclerosis: A scoping review of the literature. Mult Scler Relat Disord. 2016; 6:1-9.

Pediatric Neuroradiology

Ref No: 62

\section{Poster Presentation}

IT'S NOT HIDDEN, JUST HINDBRAIN MALFORMATION MR IMAGING AND DIFFUSION TENSOR IMAGING FEATURES OF A RARE ENTITY: PONTINE TEGMENTAL CAP DYSPLASIA

Fatma Yllmaz $^{1}$, Ayşe Aralaşmak ${ }^{2}$

${ }^{1}$ Grup Florence Nightingale Hastaneleri İstanbul Florence Nightingale Hastanesi

${ }^{2}$ Liv Hastaneleri Liv Hospital Vadistanbul

Objective: Hindbrain malformations especially related to brain stem are uncommon and rarely recognized. The difficulty of examining the brain stem also complicates the 
recognition and differentiation of its pathologies. Pontine tegmental cap dysplasia (PTCD) is one of them, only 30 cases have been reported in the literature (1) These numbers may not reflect the true prevalence due to unrecognition of the malformation or misclassification. In order to recognize the specific findings of the disease we present MR imaging and DTI features of our patient.

Case presentation:12-year-old girl followed for glaucoma has bilateral leukocoria and constant upward nystagmus referred to our radiology department. Hearing loss, growth retardation and hypotonia was also present. She had a history of preterm birth due to preeclampsia, hospitalized 2 weeks after birth, had respiratory distress and cyanosis and received $\mathrm{O} 2$ therapy, no head control and no relation to outside at that time. MRI and DTI mapping were performed. Midline sagittal T2-weighted MRI revealed ventral pontine flattening, beaklike "bump" on the dorsal surface of the pons towards to the fourth ventricle (Fig. a) and axial T2-weighted MRI showed hypoplasia of middle cerebellar peduncles (MCPs) (Fig. b) as it was reported in PTCD before. $(1,2,4)$ Axial T2-weighted MRI showed molar tooth appearance due to absence of decussation of superior cerebellar peduncle (SCP) and deep interpenducular sistern (Fig c), dysplastic vermis and absent inferior olivary prominence (Fig d) . DTI showed abcense of decussation of superior cerebelllar peduncle and ectopically located transverse pontine fibrils (3) Color coded fractional anisotropy maps showed the bundle of axons in red (arrow), directed horizontally (left-right) forming the bump (Fig. e), possibly representing "ectopic" pontine transverse fibres as reported before. $(3,5)$ This is PTCD , a nonprogressive disorder with no specific treatment. Therapy should be symptom-oriented. Joubert syndrome is included in the differential diagnosis, the posterior fossa typically shows a bat wing 4th ventricle and prominent thickened elongated superior cerebellar peduncles forming molar tooth sign.

Conclusion: Posterior fossa malformations are still not fully elucidated. The difficulty of pathological analysis of these structures and axonal pathways with inadequate MR imaging were the reasons.(3) Increased resolution in conventional MR images and evaluating white matter tracts with diffusion tensor imaging (DTI), has made neuroimaging the shining star in the assessment and classification of brain stem disorders. $(2,3,4,5)$ PTCD is a new entity that can be easily diagnosed upon recognition of its clinical and neuroimaging features. Early diagnosis is important for the detection and follow-up of other accompanying system findings.(5) Also the genetic basis and underlying mechanisms of PTCD development are still remains to be explained. (5) Recognition of PTCD neuroimaging findings will form a step towards elucidating the underlying genetic and pathognomonic mechanisms, prognostic risk information.

Keywords: Diffusion Tensor Imaging, Brain stem,

\section{References:}

1. Chris J. Cadman, Lyndsay Fraser, Claire McArthur, Radiology 2019; 291:814-818.

2. Doherty D, Millen KJ, Barkovich AJ. Midbrain and hindbrain malformations:

advances in clinical diagnosis, imaging, and genetics. Lancet Neurol 2013;12(4):381-393.

3. Jissendi-Tchofo P, Doherty D, McGillivray G, et al. Pontine tegmental cap dysplasia: MR imaging and diffusion tensor imaging findings of impaired axonal navigation. AJNR Am J Neuroradiol 2009;30:113-19.

4. Barth PG, Majoie CB, Caan MW, Weterman MA, Kyllerman M, Smit LM, Kaplan RA, Haas RH, Baas F, Cobben JM, Poll-The BT. Pontine tegmental cap dysplasia: a novel brain malformation with a defect in axonal guidance. Brain. 2007 Sep;130(Pt 9):2258-66. Epub 2007 Aug 9. PubMed PMID: 17690130.

5. Briguglio M, Pinelli L, Giordano L, et al. Pontine tegmental cap dysplasia: developmental and cognitive outcome in three adolescent patients. Orphanet J Rare Dis 2011;6:36.

Adult Neuroradiology

Ref No: 64

\section{Oral Presentation}

\section{EFFECT OF PARASPINAL MUSCLE MORPHOM- ETRY IN DEGENERATIVE AND ISTHMIC SPON- DYLOLISTHESIS: AN MRI STUDY}

Begümhan Baysal ${ }^{1}$, Mahmut Bilal Dogan ${ }^{1}$

${ }^{I}$ Istanbul Medeniyet University Goztepe Prof. Dr. Suleyman Yalcin City Hospital

Objective: Degenerative spondylolisthesis (DS) is the anterior displacement of one vertebra without any disruption of the vertebral ring, while isthmic spondylolisthesis (IS) develops due to an abnormality in the pars interarticularis. ${ }^{1,2}$ The aim of this study is to investigate the role of the cross-sectional area (CSA) of the lumbar paraspinal muscles in the development of degenerative and isthmic spondylolisthesis and its effect on the percentage of slip (PS).

Material and Methods: This retrospective single-center study included 171 patients, 100 of whom were diagnosed with isthmic and 71 patients with degenerative lumbar spondylolisthesis. First, CSAs of bilateral psoas major (PM), erector spinae (ES), and multifidus (MF) muscles were measured using T2-weighted 
axial magnetic resonance imaging (MRI), and then the ratio of muscle areas to L5 vertebral body (VB) area was calculated. The percentage of slip (PS) was found by dividing the displacement distance of the superior vertebra to the corpus AP diameter of the inferior vertebra on sagittal T2-weighted images. ${ }^{3}$ Muscle CSAs, their ratio to $\mathrm{VB}$, percentage of slip, disc height, and Modic degeneration were compared for the two groups. NCSS (Number Cruncher Statistical System) program was used for statistical analysis. The Student's t-test was used for comparisons between two groups of normally distributed quantitative variables, and the Mann-Whitney U test was used for comparisons between two groups of non-normally distributed quantitative variables.

Results: The PS rate of the degenerative group cases was found to be statistically significantly lower than the isthmic group cases $(\mathrm{p}=0.002 ; \mathrm{p}<0.01)$. The cross-sectional area of bilateral PM, bilateral MF, and right ES muscles of the patients with degenerative spondylolisthesis was found to be statistically significantly lower than the group with pars interarticularis defect $(\mathrm{p}<0.05)$ (Table). No statistically significant difference was found between the PM/VB and ES/VB measurements of the cases according to the groups ( $p>0.05$ ). The MF/VB ratio was found to be significantly lower in the degenerative group $(\mathrm{p}<0.01)$. Disc height in the degenerative group cases was found to be statistically significantly lower than in the isthmic group $(\mathrm{p}=0.007$; $\mathrm{p}<0.01$ ). There was no significant difference between the Modic changes of the cases according to the groups.

Conclusion: The cross-sectional area of all paraspinal muscle groups, especially the multifidus, was found to be lower in the degenerative group. This is valuable in explaining the etiological mechanism as well. It is also noteworthy in recommending exercises to strengthen the paraspinal muscles in the management of degenerative group patients.

Keywords: degenerative spondylolisthesis, isthmic spondylolisthesis, lumbar paraspinal muscle, percentage of slip, magnetic resonance imaging

\section{References:}

1. Matz PG, Meagher RJ, Lamer T et al. Guideline summary review: An evidence-based clinical guideline for the diagnosis and treatment of degenerative lumbar spondylolisthesis. Spine J 2016;16:439-48.

2. Kreiner DS, Baisden J, Mazanec DJ et al. Guideline summary review: an evidence-based clinical guideline for the diagnosis and treatment of adult isthmic spondylolisthesis. Spine J 2016;16:1478-85.

3. Park JH, Kim KW, Youn Y et al. Association of MRIdefined lumbar paraspinal muscle mass and slip percentage in degenerative and isthmic spondylolisthesis: A multicenter, retrospective, observational study. Medicine 2019;98(49):e18157.

4. Modic MT, Steinberg PM, Ross JS et-al. Degenerative disk disease: assessment of changes in vertebral body marrow with MR imaging. Radiology 1988;166(1):193-9.

Publisher's note Springer Nature remains neutral with regard to jurisdictional claims in published maps and institutional affiliations. 